\title{
(Almost) efficient information transmission in elections.
}

\author{
Renaud Foucart* Robert C. Schmidt ${ }^{\dagger}$
}

July 24, 2019

\begin{abstract}
We study a model in which two parties compete by announcing their policies, after receiving conditionally independent private signals about the true state of the world. Parties are both office- and policy-motivated. Our model can explain radically different policy positions, even when parties receive identical signals and have unbiased preferences. This holds in an asymmetric equilibrium in which both parties reveal their private information to the voters and the implemented policy is (almost) first-best for all possible realizations of parties' signals. In this equilibrium, one party adopts extreme and the other one moderate policy positions.
\end{abstract}

Keywords: electoral competition, signaling, intuitive criterion

JEL classification: D72, D83, Q54

\footnotetext{
${ }^{*}$ University of Nottingham, United Kingdom; E-mail: renaud.foucart@gmail.com

${ }^{\dagger}$ Institute for Microeconomics, University of Hagen, Universitätsstr. 11, 58097 Hagen, Germany; Email: robert.schmidt@fernuni-hagen.de

We would like to thank Helmut Bester, Micael Castanheira, Paul Heidhues, Steffen Huck, Navin Kartik, Roland Strausz, Xavier Venel, three anonymous referees, and an associate editor for helpful discussions and comments. We would also like to thank the audiences of various seminars and conference presentations for their inspiring comments. Financial support by the Deutsche Forschungsgemeinschaft (SCHM $2692 / 1-1)$ is gratefully acknowledged.
} 


\section{Introduction}

In this paper, we investigate how electoral competition aggregates the private information held by political parties and conveys it to voters. Consider two parties competing in an election. Each of the two parties receives a private (binary) signal from an expert, assessing the benefit of a public investment. A party commits to a (continuous) policy platform after observing its private signal, and the winner implements its announced policy after the election. While parties have access to experts' opinions, that can sometimes be conflicting, an individual voter does not have the necessary resources or incentives to become informed about this specific policy issue. However, voters may infer the experts' signals that parties have received, by observing their policy platforms.

We show that situations can arise endogenously in which two parties systematically respond differently to identical signals: while one party always responds moderately to the (private) signal it receives, the other party over-reacts to its private signal and adopts extreme policy positions. The co-existence of such a "moderate" and an "extreme" party, can be socially desirable and lead to (almost) first-best results, for any realization of the two parties' signals. We then discuss how our equilibrium predictions relate to real-world examples: the involvement of Western European countries in the 2003 Iraq war, climate policy, and nuclear electricity in Germany.

We assume that parties are both office- and policy-motivated (Callander, 2008). Their evaluation of an efficient policy is not systematically biased: if parties have access to identical information, they agree on what the socially optimal policy should look like. Hence, we abstract from systematic biases in parties' preferences, reflecting among other things differences in their constituencies, in their exposure to lobbyist groups, or in their ideology. While such factors may also play an important role in many real-world politics, our model can help to explain policy divergence - even under identical signals - and the emergence of moderate and radical parties in their absence.

We find that, if at least one party has sufficiently high policy motivation, an asymmetric equilibrium exists that successfully aggregates all available information, and where policies close to the first-best are implemented for any realization of the two parties' signals. In this equilibrium, one "moderate" party adopts a "pandering" strategy, offering a platform that is close to the optimal policy given the prior of the voters, but still transmits its signal. This party is elected under conflicting signals, and therefore implements an almost optimal policy when elected. The other party is more responsive to the information it receives and offers an "anti-pandering" platform in which it truthfully transmits its signal, but that is only optimal if two (conditionally) independent and identical signals are transmitted. This party is elected when both signals are identical, and therefore implements the optimal policy when elected. If only one party is sufficiently policy motivated, this party is the moderate one. This implies that the party that cares the least about 
the policy outcome makes the most audacious proposals, while the party that cares the most about it offers almost identical platforms regardless of the information it receives.

There also exists a symmetric revealing "anti-pandering" equilibrium in which the implemented policies are too extreme, given the limited amount of information received by each party. It is the unique symmetric revealing equilibrium of our game. In a related model, Kartik, Squintani, and Tinn (2015) show that such an anti-pandering equilibrium is the unique symmetric revealing pure-strategy equilibrium of a game with continuous state, signal, and policy spaces when both parties have pure office motivation. If office motivation is sufficiently high for both parties, a symmetric "pandering" equilibrium exists in our model where both parties announce a moderate platform and no information is revealed. Heidhues and Lagerlöf (2003) show that pandering is the unique equilibrium in a setting with binary signal and policy spaces, and pure office motivation.

A first key assumption of our model is that information is coarser than actions: a binary signal and a continuous action space. In theory, we can expect such a structure to arise when a party receives information from an expert, but their interests are not perfectly aligned. This is the classic result of Crawford and Sobel (1982): information transmission from a sender to a receiver takes the form of reporting in which element of a partition of the support of a continuous signal the sender's observation lies in. It is however a limitation of our model, made for tractability.

A second assumption is that the issue is more pragmatic than ideological. There may be political disagreement ex-ante on a how much to invest on a project. If the issue is pragmatic however, the success of a given investment is not controversial after the uncertainty is resolved. In contrast, if the issue is mostly ideological, parties and voters may continue to disagree after the fact, because they have different preferences. For instance, the cost-efficiency of a large infrastructure project seems a rather pragmatic issue. The impact of a tax-cut may be more ideological.

A third assumption is that a party is committed to implement its announced platform if elected. This assumption is standard in Downsian models in general, and in models of information transmission through the choice of political platforms in particular (Heidhues and Lagerlöf, 2003, Loertscher, 2012, Kartik et al., 2015). Commitment is an important characteristic of real-world electoral competition: voters typically see "flip-flopping" on issues - saying something one day and changing opinion later - as a negative characteristic of politicians and a sign of lower competence (see for instance Hummel, 2010). In our asymmetric equilibrium however, when parties implement the socially optimal outcome, they have no incentive to change their policy after the election. If parties were able to renege on their commitment after observing conflicting signals, the anti-pandering equilibrium would not be sustainable.

The next section reviews the related literature. We present the model in Section 
3. Section 4 provides the main results, starting with the almost efficient asymmetric equilibrium, then the revealing symmetric one and the non-revealing pandering one. We also discuss the multiplicity of equilibria and when we can expect one to be more "focal" than the others. Section 5 discusses real-world examples. We conclude in Section 6.

\section{Related Literature:}

In a closely related paper, Ambrus, Baranovskyi, and Kolb (2017) consider a situation in which an uninformed principal (corresponding to the voters in our model) chooses between one out of two experts (the candidates in our model) to do a job. As in our setup, each of the experts also receives a private signal about the state of the world. The main difference is that these authors assume that the experts are biased, while we assume that candidates have unbiased preferences, matching those of the (median) voter. Their model allows for purely policy-motivated experts, or experts that have mixed motives (as in our model).

Focusing on pure office motivation, Kartik et al. (2015) show that the welfare of the voters under political competition cannot be higher (in expectation) than in a situation in which only one party's information is available. In contrast, we show that in the presence of at least one party with sufficient policy motivation, electoral competition can deliver (almost) first-best results (given both signals). Another explanation for symmetric policy divergence in a Downsian model is provided by Bernhardt, Duggan, and Squintani (2009). These authors show that if parties only imperfectly know the preferences of the median voter, they may offer diverging platforms partly following their own bias. Laslier and Van der Straten (2004) analyze a model related to Heidhues and Lagerlöf (2003), but assume that also voters (as well as each of the parties) receive a private signal. The authors show that in equilibrium, parties truthfully reveal their signals, if voters possess sufficiently precise information. Our model also relates to Loertscher (2012). We share with this paper the assumption of binary signals and continuous policy space, together with similar concepts of equilibrium refinement. The author finds equilibria in mixed strategies in which some information is transmitted. However, he focuses on pure office motivation, so that the asymmetric equilibrium we identify is not a feature of his model.

A model in which parties are primarily policy-motivated is introduced by Schultz (1996). In contrast to our approach, Schultz (1996) does not assume that parties are uncertain about the true state of the world (only voters are). Martinelli (2001) analyzes a model in which parties with polarized preferences care about the implemented policy. Voters and parties receive noisy signals about the true state of the world. In contrast to our model (as well as Heidhues and Lagerlöf (2003) and other authors), the author assumes that both parties receive the same signal. 
The conjunction of policy and office motives for parties has been introduced by Wittman (1983) and Calvert (1985) who show that policies do not generally converge in a two-party electoral equilibrium. Building on this framework, Cukierman and Tommasi (1998) show that biased parties can offer policies at the extreme opposite of their own preferences.

Feddersen and Pesendorfer (1997) assume that voters are uncertain about the true state of the world and each voter obtains a private signal. However, the alternatives from which voters can choose are exogenously fixed and not determined via electoral competition. Gratton (2014) demonstrates in a similar framework that when policies are determined endogenously via electoral competition, voters can coordinate their votes and induce candidates to adopt the optimal policy in each state.

\section{Model}

As a running example, consider the political economy of an investment to prevent a potential catastrophe, such as climate change, a military threat or an epidemic. Suppose there are two states of the world: $G$ ('good') and $B$ ('bad'). The true state of the world is denoted by $W \in\{G, B\}$. In the good state there is no approaching catastrophe, so investment to prevent the catastrophe is not warranted. In the bad state, there is an approaching catastrophe; but the probability that it occurs can be reduced by investing $(x)$. If the catastrophe occurs, a damage of $D>0$ is incurred by society. Otherwise, the damages are assumed to be zero. The model also applies to an uncertain investment in a project delivering a positive outcome, such as an infrastructure project or a scientific innovation. The state of the world $G$ then corresponds to a case where the investment will never be successful, while state $B$ means that the investment is successful with probability $x$.

We assume that society can implement any investment $x$ in the interval $\mathbb{X}=[0,1]$. Given that $W=B$, the probability that the catastrophe occurs is then $1-x$, while it is zero when $W=G$ (irrespective of the chosen effort $x$ ). The effort $x$ is determined by the government. What we are interested in is how effective a representative democracy is in providing an optimal level of effort, given the uncertainties surrounding the problem. We assume that there are two parties, indexed $i \in\{1,2\}$, that announce policy platforms $x_{i} \in \mathbb{X}$. Then, an election takes place, and the winning party implements its announced platform.

\subsection{Information structure and payoffs}

Before parties announce their policy platforms $x_{i}(i \in\{1,2\})$, each of them receives a private signal $s_{i}$ about the true state of the world, $W$. We assume that these signals are 
binary: $s_{i} \in\{g, b\}$, where a "good" signal $\left(s_{i}=g\right)$ indicates a lower probability that a catastrophe is approaching than a "bad" signal $\left(s_{i}=b\right)$. The two parties' signals $s_{1}$ and $s_{2}$ are drawn independently from the same distribution. More specifically, we assume that each party receives a correct signal, conditional on the true state, with probability $p \in(1 / 2,1)$, hence, $\operatorname{Pr}\left[s_{i}=g \mid W=G\right]=\operatorname{Pr}\left[s_{i}=b \mid W=B\right]=p$. We focus on pure strategies. ${ }^{1}$ Hence, party $i$ 's strategy $x_{i}\left(s_{i}\right)(i \in\{1,2\})$ is a mapping from $s_{i}$ into $\mathbb{X}$. By contrast, voters do not observe any signal. We assume that nature selects $W=G$ with commonly known prior probability of $1 / 2 .^{2}$ However, after observing the policy platforms which are simultaneously announced by the two parties, voters update their belief according to Bayes' rule. We denote the voters' belief that $W=G$ after observing the platforms by $\mu\left(x_{1}, x_{2}\right)$. We assume that all voters have identical preferences. ${ }^{3}$

The cost of an investment $x$ is given by $x^{2} / 2$. Conditional on the true state of the world, voters' payoff is given by ${ }^{4}$

$$
v(W, x)= \begin{cases}-\frac{x^{2}}{2} & \text { if } W=G, \\ -\frac{x^{2}}{2}-(1-x) D & \text { if } W=B .\end{cases}
$$

Voters' preferences are thus characterized by the following (expected) utility function:

$$
\begin{aligned}
u(\mu, x) & =\mu v(G, x)+(1-\mu) v(B, x) \\
& =-x^{2} / 2-(1-\mu)(1-x) D .
\end{aligned}
$$

Given our restriction to pure strategies, party i's strategy is either fully revealing, which means that it chooses a policy platform $x_{i}(g)$ after observing a good signal that differs from its platform choice $x_{i}(b)$ after observing a bad signal, or it is non-revealing, so that $x_{i}(g)=x_{i}(b)$.

Let $\beta\left(s_{1}, s_{2}\right)$ (for belief) be the function that aggregates parties' signals when one or two signals are observed, or inferred by voters from observing policy platforms. Given our earlier assumptions about signals, we obtain the following conditional probabilities

\footnotetext{
${ }^{1}$ Heidhues and Lagerlöf (2003) and Loertscher (2012) analyze also mixed strategies.

${ }^{2}$ The case where nature selects the state $W=G$ with a probability different from $1 / 2$ is considered in the online appendix. This serves us as a robustness check.

${ }^{3}$ Hence, voters can be replaced by a 'representative voter'. Alternatively, one could assume that both parties have preferences over policies which are identical to that of the median voter.

${ }^{4}$ In the case of an investment in a project delivering a positive outcome, identical results derive from the specification

$$
v(W, x)= \begin{cases}-\frac{x^{2}}{2} & \text { if } W=G, \\ -\frac{x^{2}}{2}+x D & \text { if } W=B .\end{cases}
$$


that the true state of the world is $G$ :

$$
\begin{aligned}
& \beta_{g g} \equiv \beta(g, g)=\operatorname{Pr}\left[W=G \mid s_{1}=s_{2}=g\right]=\frac{p^{2}}{p^{2}+(1-p)^{2}}, \\
& \beta_{b b} \equiv \beta(b, b)=\operatorname{Pr}\left[W=G \mid s_{1}=s_{2}=b\right]=\frac{(1-p)^{2}}{p^{2}+(1-p)^{2}}, \\
& \beta_{g b} \equiv \beta(g, b)=\beta(b, g)=\operatorname{Pr}\left[W=G \mid s_{i}=g, s_{-i}=b\right]=1 / 2,
\end{aligned}
$$

where $\beta_{g g}, \beta_{b b}$, and $\beta_{g b}$ are introduced as short-hand notation. Note that (by (6)) two conflicting signals "cancel each other out", so that $\beta_{g b}=1 / 2$ corresponds to voters' prior belief that the true state of the world is $G$, when no signal is available. Furthermore, if only one signal $g$ (resp. $b$ ) is observed or inferred, we denote by $n$ an unobserved signal. We find for the conditional probability that the true state of the world is $G$ :

$$
\begin{aligned}
& \beta_{g} \equiv \beta(g, n)=\beta(n, g)=\operatorname{Pr}\left[W=G \mid s_{i}=g\right]=p, \\
& \beta_{b} \equiv \beta(b, n)=\beta(n, b)=\operatorname{Pr}\left[W=G \mid s_{i}=b\right]=1-p,
\end{aligned}
$$

where the latter implies that $\operatorname{Pr}\left[W=B \mid s_{i}=b\right]=p$.

As a short-hand notation, let $\hat{s}_{i}\left(x_{i}\right) \in\{g, b, n\}$ denote party $i$ 's signal as inferred by the voters after observing policy platform $x_{i}$ in three special cases. Inferred signals $\hat{s}_{i}\left(x_{i}\right) \in$ $\{g, b\}$ corresponds to voters inferring player $i$ has observed signal $\hat{s}_{i}$ with probability 1 when playing action $x_{i}$. The third element of the set, $\hat{s}_{i}\left(x_{i}\right)=n$, corresponds to voters ignoring the signal observed by player $i$. This can either correspond to the player adopting a non-revealing strategy, or to voters not inferring anything about the signal that a deviator has observed. Voters' belief that the true state of the world is $G$ in a fully revealing equilibrium $\left(x_{1}, x_{2}\right)$, is, then given by:

$$
\mu\left(x_{1}, x_{2}\right)=\beta\left(\hat{s}_{1}\left(x_{1}\right), \hat{s}_{2}\left(x_{2}\right)\right)=\beta\left(s_{1}, s_{2}\right) .
$$

Since signals are imperfect, the true state is never fully revealed. In any equilibrium and for any realization of parties' signals, it holds that $\mu\left(x_{1}, x_{2}\right) \in\left[\beta_{b b}, \beta_{g g}\right]$.

Let us finally specify parties' preferences. We assume that these are aligned with those of the voters (parties care about the efficiency of the implemented policy), but they also have an office-holding motive. The latter amounts to a fixed utility premium $f_{i} \geq 0$ for a party $i \in\{1,2\}$ that wins the election. For instance, consider some hypothetical situation where party $i$ is elected with probability one when offering platform $x_{i}$. Its expected utility is then given by

$$
u\left(\beta\left(s_{i}, n\right), x_{i}\right)+f_{i},
$$


where $x_{i}$ is the implemented policy, and $\beta\left(s_{i}, n\right)$ is the party's belief that $W=G$ after observing its private signal, but not the signal of the other party. A complete description of parties' expected utility is provided in Section 3.4.

As signals convey information about the true state of the world, one's signal also conditions the expectation of the signal observed by the other party. For instance, party 1's expectation about the likely realization of party 2's signal, after observing its own private signal $s_{1}$, is captured by the following conditional probability:

$$
\pi \equiv \operatorname{Pr}\left[s_{2}=g \mid s_{1}=g\right]=\operatorname{Pr}\left[s_{2}=b \mid s_{1}=b\right]=p^{2}+(1-p)^{2},
$$

where $\pi$ is again a short-hand notation.

\subsection{Voting behavior}

Conditional on their belief $\mu=\mu\left(x_{1}, x_{2}\right)$ that the true state of the world is $G$, voters' most preferred policy (in $\mathbb{X}$ ) is:

$$
\tilde{x}=(1-\mu) D
$$

This follows simply from maximizing (3) over $x$. We restrict the size of the damages $D$ so that $\tilde{x} \leq 1$ is always satisfied. This requires that $\tilde{x} \leq 1$ holds for the most pessimistic beliefs that can occur, i.e., $\mu=\beta_{b b}$, which leads to the parameter restriction $D \leq \pi / p^{2}$. If parties announce different platforms, voters prefer policy $x_{1}$ over $x_{2}$ (given $\mu$ ) if

$$
u\left(\mu, x_{1}\right)>u\left(\mu, x_{2}\right)
$$

which is equivalent to (using (3) and (11))

$$
\left|\tilde{x}-x_{1}\right|<\left|x_{2}-\tilde{x}\right|
$$

Hence, party 1 is elected with probability 1 if and only if its announced policy is closer to their most preferred policy, $\tilde{x}$. This property allows us to directly compare our results to the ones in Ambrus et al. (2017) and Kartik et al. (2015), in which voters have a quadratic loss function of being away from their most preferred policy. We further assume that ties are broken randomly at equilibrium so that each party is elected with probability $1 / 2$ when no off-path ${ }^{5}$ policy platform is chosen by any party and voters are indifferent between the platforms $x_{1}$ and $x_{2}$ (given their belief $\mu\left(x_{1}, x_{2}\right)$ ). We discuss in Section 4.1 how tie-breaking-rules affect the existence of equilibria in the case where voters are indifferent

\footnotetext{
${ }^{5}$ Throughout this paper, we refer to "off-path" actions as actions that should never be chosen by a player if this player sticks with her equilibrium strategy (for any realization of her signal), whereas "out-of-equilibrium" actions are deviations in general, including a deviation to a policy that should be played after receiving the opposite signal.
} 
between an on-path policy platform of one party and an off-path platform of the other party.

We express the voting behavior by a function $\sigma\left(x_{1}, x_{2}\right)$, which is the probability of electing party 1 when parties announce platforms $\left(x_{1}, x_{2}\right)$. Given our above assumptions, in any pure-strategy equilibrium, $\sigma$ can only take on the values $0,1 / 2$, and 1 .

\subsection{Social optimum}

In order to understand parties' platform choices, we first need to characterize the social optimum, defined as the utility of the representative voter, given the informational constraints. This social optimum would be obtained if both parties' signals were made public, and voters could directly choose their most preferred policy in $\mathbb{X}=[0,1]$, given their updated belief about the probability that $W=G$. When $s_{1}=s_{2}=g$, then $\mu=\beta_{g g}$ (see (4)), so that (by (11)) the optimal policy is

$$
x_{g g}^{*} \equiv\left(1-\beta_{g g}\right) D=\frac{(1-p)^{2} D}{p^{2}+(1-p)^{2}} .
$$

Similarly, when $s_{1}=s_{2}=b$ then the most preferred policy is $x_{b b}^{*} \equiv\left(1-\beta_{b b}\right) D$. When signals differ, the optimal policy is $x_{g b}^{*} \equiv\left(1-\beta_{g b}\right) D=D / 2$. We refer to $D / 2$ also as the "neutral policy": the optimal policy when no signal is revealed.

Let us also characterize the optimal policy when only one signal is revealed. Then we obtain

$$
x_{g}^{*} \equiv\left(1-\beta_{g}\right) D=(1-p) D
$$

if the signal is $g$, and $x_{b}^{*} \equiv\left(1-\beta_{b}\right) D=p D$ if the signal is $b$.

We illustrate the optimal platform choices in Figure 1 (for the parameter values $D=1$ and $p=0.7)$. Observe that $x_{g}^{*}$ and $x_{b}^{*}$, resp. $x_{g g}^{*}$ and $x_{b b}^{*}$, are located symmetrically around the neutral policy $D / 2=x_{g b}^{*}$.

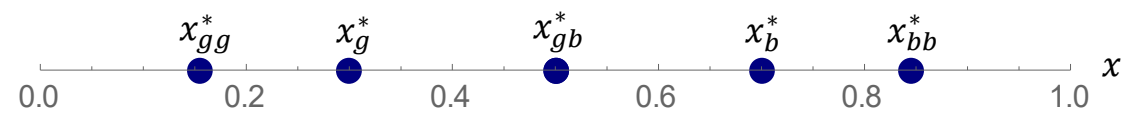

Figure 1: Optimal policies, for $p=0.7$ and $D=1$

Later, we analyze "symmetric revealing equilibria". These are equilibria in which each party chooses a policy platform $x_{g}$ if it observes a good signal, and platform $x_{b}$ if it observes $b$. The qualifier "symmetric" refers to the restriction that these two values are the same for both parties; and "revealing" means that the two platforms $x_{g}$ and $x_{b}$ differ, so that voters can infer the signal of each party that is playing this strategy. As a benchmark for such equilibria, let us here analyze how such policies $x_{g}$ and $x_{b}$ that 
satisfy these constraints would be chosen optimally in order to maximize the expected utility of the voters, and compare it to the social optimum. Because policies that are located symmetrically around the neutral policy will turn out to play a central role later on, we also study a case with the additional restriction: $x_{b}=D-x_{g}$.

Lemma 1. Assume both signals are revealed:

1. The policies $x_{g}=x_{g g}^{*}$ (when $s_{1}=s_{2}=g$ ), $x_{b}=x_{b b}^{*}$ (when $s_{1}=s_{2}=b$ ) and $x_{g b}=x_{g b}^{*}$ (when $s_{1} \neq s_{2}$ ) deliver the highest expected utility to the voters.

2. If only two different policies can be implemented $\left(x_{g}\right.$ and $\left.x_{b}\right)$, then the policies $x_{g}=x_{g g}^{*}$ (when $s_{1}=s_{2}=g$ ) and $x_{b}=\tilde{x}_{b}{ }^{6} \in\left(x_{g b}^{*}, x_{b}^{*}\right)$ (in all other cases) deliver the highest expected utility to the voters. Those policies are welfare equivalent to the mirror $x_{b}=x_{b b}^{*}$ (when $s_{1}=s_{2}=b$ ) and $x_{g}=\tilde{x}_{g}=1-\tilde{x}_{b} \in\left(x_{g}^{*}, x_{g b}^{*}\right)$ (in all other cases).

3. If only two different policies can be implemented $\left(x_{g}\right.$ and $\left.x_{b}\right)$, with the additional constraint that $x_{b}=D-x_{g}$, then the policies $x_{g}=x_{g}^{*}=(1-p) D$ and $x_{b}=x_{b}^{*}=p D$ deliver the highest expected utility to the voters .

Given the restriction that at most two different policies can be implemented, the (unconstrained) social welfare optimum cannot be implemented since there are three different realizations of voters' most preferred policy, given the underlying information structure. The first point of the lemma follows directly from our definition of optimal policies. The second point shows that it is possible to design "skewed" policies such that one of the two policy is "extreme" and played only when the two signals are identical, while the other is "moderate" and played in all other circumstance. Those perform (slightly) better than policies symmetric around the "neutral policy" $x_{g b}^{*}=D / 2$, corresponding to the restriction $x_{b}=D-x_{g}$. Observe, that the policies $x_{g}^{*}=(1-p) D$ and $x_{b}^{*}=p D$ are also voters' preferred policies when only one signal is revealed. ${ }^{7}$

\subsection{Political competition}

In a Perfect Bayesian Equilibrium (PBE), party $i$ chooses its policy platform $x_{i}$ so as to maximize its expected utility, given the strategy of the other party: $x_{-i}\left(s_{-i}\right)$. Assuming that party 2 adopts strategy $x_{2}\left(s_{2}\right)$, and that voters respond to platform choices $\left(x_{1}, x_{2}\right)$ with beliefs $\mu\left(x_{1}, x_{2}\right)$ that lead to an optimal voting probability for party 1 of $\sigma\left(x_{1}, x_{2}\right)$, the

\footnotetext{
${ }^{6}$ The precise value is $\tilde{x}_{b}=D \frac{(2-p) p}{1-2(1-p) p}$, but it plays no role in our subsequent analysis.

${ }^{7}$ Under the constraint of symmetric policies around $x_{g b}^{*}$, Lemma 1 is thus reminiscent of Theorem 2 in Kartik et al. (2015) showing that any equilibrium where both parties are elected with positive probability yields the voter strictly lower ex-ante expected utility than in a situation where one party is always elected, offering the optimal policy conditional on its signal.
} 
expected utility of party $1, E_{s_{2} \mid s_{1}} U_{1}\left(s_{1}, s_{2}, x_{1}, x_{2}\left(s_{2}\right), \sigma\left(x_{1}, x_{2}\left(s_{2}\right)\right)\right)$, given that it received signal $s_{1}$ and chooses policy platform $x_{1}$, is given by

$$
\mathrm{E}_{s_{2} \mid s_{1}}\left[\sigma\left(x_{1}, x_{2}\left(s_{2}\right)\right)\left(u\left(\beta\left(s_{1}, s_{2}\right), x_{1}\right)+f_{1}\right)+\left(1-\sigma\left(x_{1}, x_{2}\left(s_{2}\right)\right)\right) u\left(\beta\left(s_{1}, s_{2}\right), x_{2}\left(s_{2}\right)\right)\right] .
$$

Consider again the case of symmetric revealing strategies. Assuming that party 2 sticks with the equilibrium strategy (i.e., $x_{2}(g)=x_{g}$ and $\left.x_{2}(b)=x_{b}\right)$, the above expectation becomes for an arbitrary choice of $x_{1}$ :

$$
\begin{aligned}
& \operatorname{Pr}\left[s_{2}=g \mid s_{1}\right]\left[\sigma\left(x_{1}, x_{g}\right)\left(u\left(\beta\left(s_{1}, g\right), x_{1}\right)+f_{1}\right)+\left(1-\sigma\left(x_{1}, x_{g}\right)\right) u\left(\beta\left(s_{1}, g\right), x_{g}\right)\right] \\
+ & \operatorname{Pr}\left[s_{2}=b \mid s_{1}\right]\left[\sigma\left(x_{1}, x_{b}\right)\left(u\left(\beta\left(s_{1}, b\right), x_{1}\right)+f_{1}\right)+\left(1-\sigma\left(x_{1}, x_{b}\right)\right) u\left(\beta\left(s_{1}, b\right), x_{b}\right)\right] .
\end{aligned}
$$

Note that given our earlier assumptions it holds that $\sigma\left(x_{g}, x_{g}\right)=\sigma\left(x_{b}, x_{b}\right)=1 / 2$. Furthermore, in the special case where the equilibrium platform choices $x_{g}$ and $x_{b}$ are located symmetrically around the neutral policy, we have

$$
\sigma\left(x_{g}, x_{b}\right)=\sigma\left(x_{b}, x_{g}\right)=1 / 2
$$

since voters do not learn anything from observing contrasting platforms in a symmetric revealing equilibrium, and each of the policies $x_{g}, x_{b}$ then yields an identical expected welfare.

\subsection{Equilibrium concept}

Given our earlier assumptions, we can summarize our model as follows. There are three strategic players: party 1, party 2, and the voters acting as one player. In the first move, nature picks the state of the world, $W \in\{G, B\}$ (each with a probability of $1 / 2)$, and signals $s_{i} \in\{g, b\}$ for party $i \in\{1,2\}$ with $\operatorname{Pr}\left[s_{i}=g \mid W=G\right]=\operatorname{Pr}\left[s_{i}=\right.$ $b \mid W=B]=p$. In the second move, the two parties simultaneously choose action (platform) $\left\{x_{1}, x_{2}\right\} \in \mathbb{X}$, after observing only their own signal. Finally, voters choose action $\sigma \in[0,1]$ (the probability with which they elect party 1 ), after observing only $x_{1}$ and $x_{2}$ (and not $s_{1}, s_{2}$, or $W$ ). Assuming that the other party adopts strategy $x_{-i}\left(s_{-i}\right)$, and that voters elect party 1 with a probability of $\sigma\left(x_{1}, x_{2}\right)$, party $i$ 's expected utility $(i=1,2)$ is $E_{s_{-i} \mid s_{i}} U_{i}\left(s_{i}, s_{-i}, x_{i}, x_{-i}(\cdot), \sigma(\cdot, \cdot)\right)$, as defined in (14) for party 1 (similarly for party 2$)$.

In the context of this model, a Perfect Bayesian Equilibrium (PBE) is a profile of strategies $\left(x_{1}^{*}(\cdot), x_{2}^{*}(\cdot), \sigma^{*}(\cdot, \cdot)\right)$, combined with voters' beliefs that assign a probability of $\mu\left(x_{1}, x_{2}\right)$ to the state $W=G$, conditional on observing actions $x_{1}, x_{2} \in \mathbb{X}$, such that

(i) party $i$ 's strategy is optimal given the strategy of party $-i$ and voters' strategy $\sigma^{*}(\cdot, \cdot)$, for $i=1,2$, 
(ii) voters' beliefs $\mu\left(x_{1}, x_{2}\right)$ are consistent with parties' strategies $x_{1}^{*}\left(s_{1}\right)$ and $x_{2}^{*}\left(s_{2}\right)$, and

(iii) the voters' strategy is optimal for each $\left(x_{1}, x_{2}\right)$, given voters' beliefs $\mu\left(x_{1}, x_{2}\right)$.

We further assume that if one party plays an action that is consistent with the equilibrium strategy of that player (i.e., should be played for some realization of this player's signal), whereas the other party chooses an "off-path" action that should never be played according to the equilibrium strategy of that player (for any realization of his signal), voters rationalize the observed actions with the fewest deviations and therefore identify the party playing an off-path strategy as the deviator (Bagwell and Ramey, 1991). We need this assumption when studying whether a unilateral deviation from an equilibrium to such an action can be profitable.

It is well-known that models such as this one may display a large number of PBE, some of them relying on out-of equilibrium beliefs that are not plausible. For this reason it is useful to introduce a refinement criterion. Following the idea of Cho and Kreps (1987) in a one-sender, one-receiver game, our goal is to identify unilateral deviations from a proposed equilibrium strategy to an action $x_{i}^{\prime}$, that would never be profitable for party $i$ after observing one (and only one) of the two possible realizations $(g / b)$ of signal $s_{i}$, irrespective of what voters might infer about the signal that this party received. In that case, the intuitive criterion of Cho and Kreps (1987) requires that voters put zero probability on that realization of the signal $s_{i}$ when they observe the off-path policy platform $x_{i}^{\prime}$.

A formal definition of the equilibrium refinement is provided for interested readers in Appendix A. Furthermore, we show that when considering whether a deviation could be profitable for some beliefs, it is enough to verify whether it is profitable for extreme beliefs $\hat{s}_{i}\left(x_{i}^{\prime}\right) \in\{g, b\}$.

\section{Results}

Let us now proceed to the results of the model. While most authors so far have focused on symmetric equilibria, we show the existence of asymmetric equilibria (almost) efficiently aggregating the information received by the two parties. When there are only two parties or candidates, with any symmetric equilibrium, at most two different policies can be implemented, while four different policies can be implemented in an asymmetric equilibrium. An asymmetric equilibrium is therefore a natural candidate to reach the social welfare optimum, because in the latter there are only three different policies that need to be implemented $\left(x_{g g}^{*}, x_{b b}^{*}\right.$, and $\left.x_{g b}^{*}\right)$, depending on the realization of the two signals. ${ }^{8}$

\footnotetext{
${ }^{8}$ Another approach allowing to implement more than two different equilibrium policies would be to consider a third party always offering the "neutral" policy $D / 2$. Felgenhauer (2012) studies cases in which
} 
Subsequently, we also analyze symmetric revealing equilibria, and non-revealing (pandering) equilibria. Such equilibria have also been analyzed by other authors, in related frameworks. Our contribution is to identify when they exist in the presence of policy motivation. Using results from behavioural economics and the study of focal points we then discuss when we can expect to observe each equilibrium.

\subsection{Asymmetric revealing equilibria}

Consider the following (candidate) equilibrium. Suppose, party 1 offers policy platforms near the extremes of the policy space, that is, $x_{1}=x_{g g}^{*}$ if $s_{1}=g$ and $x_{1}=x_{b b}^{*}$ if $s_{1}=b$. By contrast, party 2 offers platforms in the center of the policy space. For a social optimum, it is necessary that both parties are able to convey their private information truthfully and credibly to the voters. Hence, the case where party 2 always offers the platform $x_{g b}^{*}=D / 2$, irrespective of its signal, cannot lead to the social optimum. However, that platform choice is optimal whenever the two signals are conflicting. One way to resolve this problem would be to add a "cheap talk" stage to the game where party 2 can announce whether it received a good or a bad signal, independently of its actual platform choice. In order to avoid such a change in the structure of the game, we assume instead that party 2 announces a platform choice of $D / 2-\alpha$ when it receives a good, and $D / 2+\alpha$ when it receives a bad signal, where $\alpha$ is a (small) positive number. This way, party 2's platform choice is still 'revealing', yet, in the limit case where $\alpha \rightarrow 0$, the implemented policy effectively leads to the same welfare as the policy $x=D / 2$ whenever this party is elected.

Definition 1. A strategy $x_{i}(s)$ is extreme if $x_{i}(s)=x_{s s}^{*}$ for any $s \in\{g, b\}$. Instead, it is moderate if there exists $\alpha>0$ such that $x_{i}(b)=D / 2+\alpha<x_{b b}^{*}$ and $x_{i}(g)=D / 2-\alpha>x_{g g}^{*}$.

While it is possible to construct a variety of out-of-equilibrium beliefs such that an asymmetric equilibrium with an extreme and a moderate party exists, we focus our attention on the intuitive criterion. The intuitive criterion implies that voters correctly infer the only signal realization for which a deviation to $x_{i}^{\prime}$ is profitable, for some beliefs of the voters, if such a deviation exists.

Proposition 1. 1. Define fopt $\equiv \frac{D^{2}}{8\left(1-2 p+2 p^{2}\right)^{2}}>0$. For all $f_{2}<f^{o p t}$, there exists some $\bar{\epsilon}>0$ such that for all $\epsilon \in(0, \bar{\epsilon}]$ an asymmetric equilibrium satisfying the intuitive criterion in which party 1 plays an extreme strategy and party 2 plays a moderate strategy $x_{2}(b)=D / 2+\epsilon$ and $x_{2}(g)=D / 2-\epsilon$ exists.

such a completely uninformed candidate can restore efficiency. This approach has its own limitations. Some voting systems make it difficult for more than two parties to co-exist and finance elections. It is also unlikely that a party identified as incompetent wins an election including other issues. 
2. There exists $f^{\text {asym }}>f^{\text {opt }}$ such that, if $f_{2}<f^{\text {asym }}$, then there exists an asymmetric equilibrium satisfying the intuitive criterion in which party 1 plays an extreme strategy and party 2 plays a moderate strategy $x_{2}(b)=D / 2+\alpha<x_{b b}^{*}$ and $x_{2}(g)=D / 2-\alpha>x_{g g}^{*}$, with $\alpha>0$.

In such an asymmetric equilibrium, we have two clearly identifiable parties playing different strategies. One party is "moderate" in the sense that it conveys its message while offering a "safe" platform in case the message of the other party is conflicting. The second party is "extreme" in the sense that it offers the anti-pandering policy $x_{g g}^{*}$ (resp. $x_{b b}^{*}$ ), depending on its signal. Only one party (the moderate one) has to be sufficiently policy-motivated for the equilibrium to exist. The less this party is policy-motivated, the less moderate policy it can offer in equilibrium. The extreme party can have any kind of motivation, as it benefits both from being elected whenever the other party obtains an identical signal (with a probability greater than $1 / 2$ ) and from seeing the almost socially optimal policy being implemented for any realization of $s_{1}$ and $s_{2}$.

As parties are clearly identifiable, the equilibrium can be sustained even for parameter values for which the moderate party might mimic the anti-pandering strategy of the extreme one. The equilibrium then exists if, when indifferent, voters elect the non-deviating party. This strategy seems natural as voters never lose from applying it and can sustain the equilibrium that brings them the highest utility for a larger range of parameters. Such a pattern of voters "preferring the original" is often described as characterizing extreme-right votes surges when a moderate right-wing party tries to move too far to the right (see Arzheimer, 2009). Our model gives a simple theoretical explanation for such patterns: as voters benefit from the existence of a moderate party, it is in their interest to ensure it remains moderate, and there is no cost of doing so.

While there is some freedom in the "design" of an asymmetric equilibrium regarding the exact choice of the moderate party's policy platforms, the equilibrium policy platforms of the extreme party are always $x_{g g}^{*}$ (resp. $x_{b b}^{*}$ ). Those extreme platforms correspond to the social optimum for the case where two conforming signals are revealed. The moderate party's platforms are located symmetrically around the neutral policy, but there remains a range of distances to $D / 2$ such that an asymmetric equilibrium exists. As both parties and voters have the same objective function regarding the implemented policy, it seems reasonable to focus on the case where voters and parties coordinate on an equilibrium with the smallest possible distance to the neutral policy, such that party 2 can still credibly convey its signal to the voters via its platform choice. If $f_{2}$ is sufficiently small $\left(f_{2}<f^{o p t}\right)$, then the distance to $D / 2$ can be arbitrarily small. Indeed, party 2 then only deviates from the neutral policy in order to convey its signal. By contrast, if $f_{2}$ is larger but not too large $\left(f^{o p t}<f_{2} \leq f^{\text {asym }}\right.$ ), then the distance to the neutral policy must be larger, in order to render a deviation to $D / 2+\alpha$ after observing $s_{2}=g$ (and vice versa) 


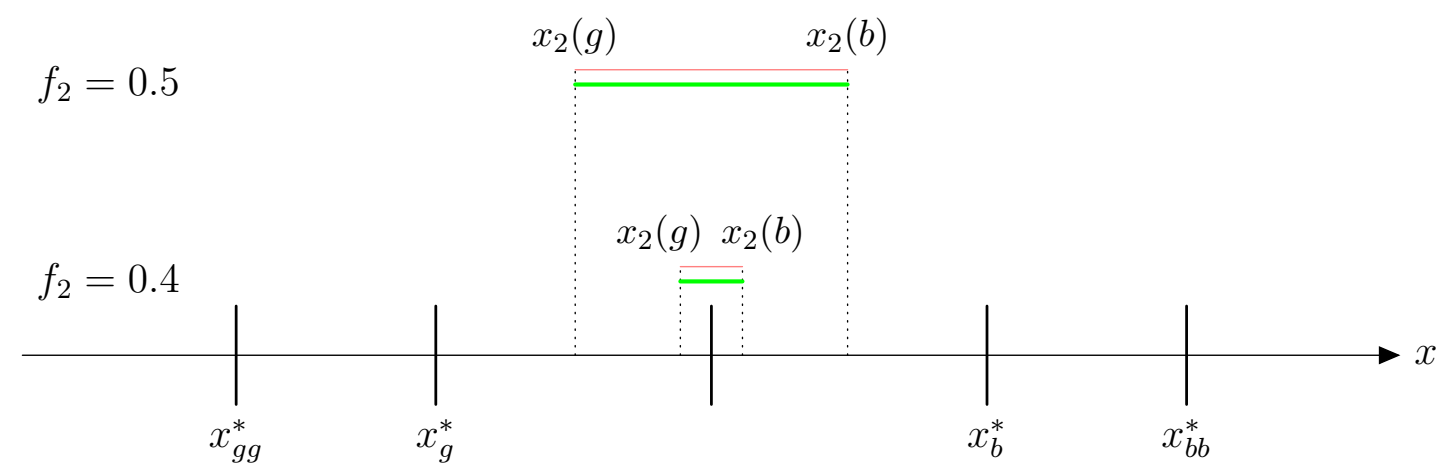

Figure 2: Profitable deviations from the asymmetric equilibrium strategies for the moderate party 2 for some beliefs; thick green line: after observing $s_{1}=g$; thin red line: $s_{1}=b$, for $D=1, p=0.7$, with $x_{2}(g)=D / 2-\alpha$ and $x_{2}(b)=D / 2+\alpha$.

unprofitable. When the office motivation of the moderate party converges to the threshold $f^{a s y m}$, its strategy converges to the strategy of the extreme party. Therefore, under the intuitive criterion, the asymmetric equilibrium presented in this section "converges" to a symmetric anti-pandering equilibrium when both parties' office motivation becomes sufficiently large. We study such a symmetric equilibrium in the next section.

We illustrate this equilibrium in Figure 2. The bottom part corresponds to a parameter value of $f_{2}=0.4$. For this parameter value, the asymmetric equilibrium exists, with $\alpha$ strictly positive as $f^{o p t}<f_{2}<f^{a s y m}$. The green (red) line at the center illustrates the platform choices $x_{2}$ to which party 2 could profitably deviate under some beliefs of voters about the realization of $s_{2}$, after observing $s_{2}=g$ (resp. $s_{2}=b$ ). We know (see Appendix A) that in order to identify such deviations it is enough to focus on the most extreme beliefs $\hat{s}_{i}\left(x_{i}\right) \in\{g, b\}$. The lines are fully overlapping because a deviation to a policy in this range is profitable whenever voters infer that party 2 's signal was either good or bad (depending on $s_{1}$ ). Hence, the intuitive criterion does not restrict out-of-equilibrium beliefs. We show in the proof of Proposition 1 that for any policy $x \in(D / 2-\alpha, D / 2+\alpha)$ out-of-equilibrium beliefs such that no party offering this policy is ever elected when the other party plays an extreme strategy $x_{g g}^{*}$ or $x_{b b}^{*}$ can always be constructed. Hence, a "moderate" strategy can span a large policy space and become arbitrarily close to $x_{b b}^{*}$ (resp. $x_{g g}^{*}$ ), corresponding to our condition $f<f^{\text {asym }}$. Other standard refinements such as Universal Divinity ${ }^{9}$ (Banks and Sobel, 1986) or Perfect Sequential Equilibrium ${ }^{10}$ (PSE,

\footnotetext{
${ }^{9}$ In our model the set of best-responses to a policy choice that can be beneficial after observing one signal is not included in the set of best-responses that can be beneficial after observing the other signal, unless when the deviation is never profitable for one signal. We can thus never say that one deviation is "more likely" than the other if a deviation to some $x^{\prime}$ is profitable for some beliefs for player $i$ after observing both signals. See appendix B of Callander (2008) for a formal definition of Universal divinity in the context of a voting model.

${ }^{10}$ Translating into our notation, the PSE algorithm works as follows. First, if a deviation to some $x^{\prime}$ is profitable for some beliefs for player $i$ after observing both signals, impose that voters ignore the signal received by player $i, \hat{s}_{i}\left(x^{\prime}\right)=n$. Second, for a deviation to such a $x^{\prime}$ to be profitable under PSE it must
} 
Grossman and Perry, 1986) do not rule out such out-of-equilibrium beliefs.

An important characteristic of the asymmetric equilibria we characterize here is that each of the two parties is identified as being either "moderate" or "extreme", for each realization of its signal. The reason is that parties alternating being moderate or extreme depending on the signal they receive would not permit to reach the (almost) efficient outcome of Proposition 1. Consider an asymmetric equilibrium where, say, party 1 plays $x_{1}(g)=x_{g g}^{*}$ and $x_{1}(b)=D / 2$, while party 2 plays $x_{2}(g)=D / 2$ and $x_{2}(b)=x_{b b}^{*}$. Such an equilibrium cannot lead to the first-best because for $s_{1}=g$ and $s_{2}=b$ an extreme policy is always implemented.

\subsection{Symmetric revealing equilibria}

As indicated in Section 3.3, a "symmetric revealing equilibrium" consists of two choices, $x_{g}$ and $x_{b}$, such that party $i$ chooses $x_{i}=x_{g}$ if $s_{i}=g$ and $x_{i}=x_{b}$ if $s_{i}=b$. In the analysis of symmetric revealing equilibria, we sometimes refer to $x_{g}$ and $x_{b}$ as 'strategies', when $x_{i}(g)=x_{g}$ and $x_{i}(b)=x_{b}$ holds for both parties.

It is possible to show that if voters ignore off-path platform choices in their formation of beliefs, the symmetric policies $x_{g}^{*}$ and $x_{b}^{*}$ described in the third part of Lemma 1 constitute a PBE (see online Appendix). However, the result comes with the caveat that voters ignore the information transmitted by a party playing some off-path platform $x_{i}^{\prime}$, even if the only possible signal for which such a deviation is profitable under some beliefs is $g$ (resp. $b$ ). For example, if party 1 receives signal $s_{1}=g$, then a deviation to $x_{1}^{\prime}=x_{g g}^{*}$ is profitable when voters infer $\hat{s}_{1}\left(x_{1}^{\prime}\right)=g$. Then if $s_{2}=g$, party 1 is elected for sure (rather than with a probability of $1 / 2$ - as in equilibrium), and in addition, it implements a policy that is (in expectation) superior to the policy that would be implemented in equilibrium. It is straight-forward to show that the deviation leads to an increase in party 1's expected payoff. Conversely, if $s_{1}=b$ then party 1 has no incentive to deviate to $x_{1}^{\prime}=x_{g g}^{*}$, irrespective of voters' beliefs. Such an equilibrium therefore does not satisfy the intuitive criterion.

This intuition is actually more general and applies to any candidate equilibrium in which parties play symmetric revealing strategies not corresponding to the anti-pandering ones $\left(x_{g g}^{*}, x_{b b}^{*}\right)$.

Lemma 2. There are no out-of-equilibrium beliefs satisfying the intuitive criterion such that symmetric revealing strategies $\left(x_{g}, x_{b}\right) \neq\left(x_{g g}^{*}, x_{b b}^{*}\right)$ constitute an equilibrium.

actually be profitable both when $s_{i}=g$ and $s_{i}=b$ given that $\hat{s}_{i}\left(x^{\prime}\right)=n$. In the asymmetric equilibrium, there is no such profitable deviation: a deviation to some $x^{\prime}$ smaller (resp. higher) than $x_{g b}^{*}$ can only be profitable for beliefs $\hat{s}_{i}\left(x^{\prime}\right)=n$ after $s_{i}=g$ (resp. $s_{i}=b$ ). Hence, PSE yields the same outcome as the intuitive criterion. The same holds for the symmetric equilibrium studied in the next section. Loertscher (2012) applies the PSE in a voting context. 


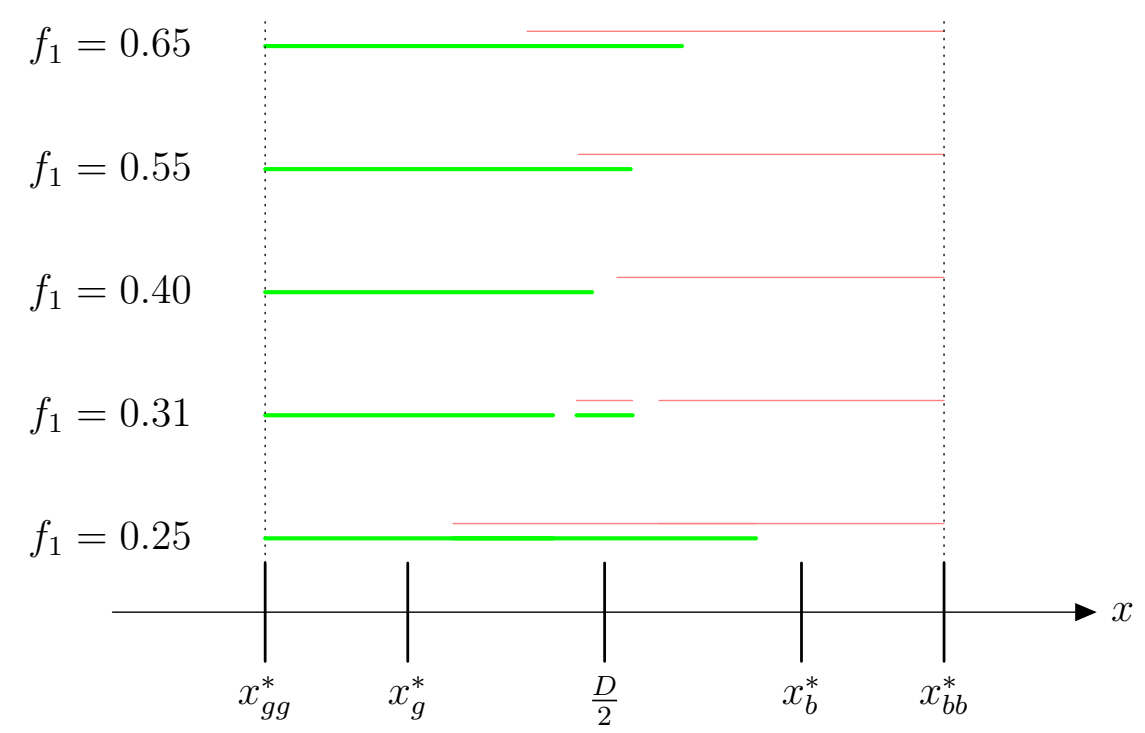

Figure 3: Profitable deviations from the equilibrium strategies $\left\{x_{g g}^{*}, x_{b b}^{*}\right\}$ for some beliefs; thick green line: after observing $s_{1}=g$; thin red line: $s_{1}=b$, for $D=1, p=0.7$

The profitable deviations that are underlying this (negative) result are generally towards the anti-pandering strategy $x_{g g}^{*}\left(\right.$ if $x_{g} \neq x_{g g}^{*}$ ), resp. to $x_{b b}^{*}$ (if $x_{b} \neq x_{b b}^{*}$ ). Only in the special case where one of the two strategies $\left(x_{g}, x_{b}\right)$ is already the corresponding antipandering strategy $\left(x_{g g}^{*}\right.$, resp. $\left.x_{b b}^{*}\right)$, while the other one is not, the profitable deviations underlying Lemma 2 may be different, but it is still possible to show that there exist profitable deviations under the intuitive criterion. ${ }^{11}$

The above result implies that there exists only one candidate PBE with symmetric revealing strategies satisfying the intuitive criterion, corresponding to the anti-pandering strategies $x_{g g}^{*}$ and $x_{b b}^{*}$. Our next result shows that such an equilibrium always exists.

Proposition 2. There always exists a symmetric revealing equilibrium satisfying the intuitive criterion in which parties adopt the anti-pandering 'strategies' $x_{g g}^{*}$ and $x_{b b}^{*}$.

We illustrate on Figure 3 the logic behind this equilibrium, by studying whether there exist profitable unilateral deviations for party 1 when party 2 plays the equilibrium strategy.

The top of Figure 3, plotted for $f_{1}=0.65$, corresponds to a party 1 with high office motivation. The thick green lines show how far away from $x_{g g}^{*}$ party 1 is willing to go after observing $s_{1}=g$ while misleading the voters to believe it has observed $s_{1}=b$ with sufficiently high probability. The tin red line shows how far away from $x_{b b}^{*}$ party 1 is willing to go after observing $s_{1}=b$. When the line are not overlapping, the intuitive criterion requires voters to correctly infer the signal and the deviation is not profitable. When they are overlapping, we have shown in the previous subsection that it is always possible to construct out-of-equilibrium beliefs satisfying the intuitive criterion such that

\footnotetext{
${ }^{11}$ The proof of this specific aspect is a bit involved and provided in an online appendix.
} 
party 1 is never elected when unilaterally deviating to $x_{1}^{\prime}$ against party 2 playing the anti-pandering strategy. When office motivation decreases $\left(f_{1}=0.55\right.$ and $\left.f_{1}=0.40\right)$, the overlapping part shrinks and eventually disappears.

Then, for even lower office motivation, we start to observe potential policy motivated deviations. Party 1 is willing to reduce its chances of being elected in order to improve the quality of the implemented policy under conflicting signals. This is the reason why we observe again profitable deviations around the neutral policy $D / 2$, for some beliefs, for $f_{1}=0.31$. The deviations are symmetric around $D / 2$ because they are only profitable if the deviating party would be elected under conflicting signals, in which case it is indifferent between policies equidistant from $D / 2$ as $\mu=1 / 2$. Hence, it is possible to construct out-of-equilibrium beliefs satisfying the intuitive criterion such that party 1 deviating towards the center is never elected. The same holds when when office motivation decreases even more $\left(f_{1}=0.25\right)$ and the overlapping lines stretch further away from $D / 2$.

While Proposition 2 implies that an anti-pandering equilibrium always exists and satisfies the intuitive criterion, a crucial assumption is that the ex-ante probability of the state being good is exactly $1 / 2$. Else, voters are not indifferent between $x_{g g}^{*}$ and $x_{b b}^{*}$ when signals are conflicting (see Loertscher, 2012). Consider the case where $x_{g g}^{*}$ is preferred to $x_{b b}^{*}$ when signals are conflicting: for the highest levels of office motivation, a party could deviate from the anti-pandering equilibrium by choosing policy $x_{g g}^{*}$ upon observing signal $b$, and be elected with probability one when the other also observed $b$, and with probability $1 / 2$ when the other observed $g$. For a symmetric anti-pandering equilibrium satisfying the intuitive criterion to exist with ex-ante probability different from $1 / 2$, policy motivation must therefore be sufficiently high for a party to trade-off a higher probability of being elected for a better policy. We show in the online Appendix that our asymmetric equilibrium is however robust to such skewed beliefs. Indeed, in this equilibrium, two players never offer an extreme platform at the same time, so that it does not matter whether voters prefer one or the other when parties transmit different signals. As from Lemma 2, no other symmetric revealing equilibrium exists.

\subsection{Non-informative equilibrium}

When both parties have high office motivation, a non-informative "pandering" equilibrium exists, similar in spirit to the one described by Heidhues and Lagerlöf (2003).

Proposition 3. There exists a symmetric "pandering" equilibrium satisfying the intuitive criterion where both parties offer the platform $x=D / 2$ regardless of the signal they receive if and only if for both parties, office motivation is sufficiently high $\left(f_{i}>f^{p}\right)$.

The idea behind the pandering equilibrium is that if both parties have sufficiently strong office motivation, voters cannot infer anything from a party deviating from the 
equilibrium strategy as any deviation that manages to attract voters would be profitable regardless of the signal received. Hence, there is no profitable deviation from the "pandering strategy" $x_{i}(g)=x_{i}(b)=D / 2(i=1,2)$. This result mirrors the results of Heidhues and Lagerlöf (2003) and Loertscher (2012) who restrict their attention to purely officemotivated parties. When office motivation is low however, there are some deviations profitable only after observing the "right" signal.

\subsection{Equilibrium selection}

Combining Propositions 1, 2 and 3, we observe that the game displays multiple equilibria satisfying the intuitive criterion. For the highest levels of office motivation, the antipandering equilibrium coexists with the non-revealing pandering one. If, for at least one party, office motivation is low enough $\left(f_{i} \leq f^{\text {asym }}\right.$ for one $\left.i \in\{1,2\}\right)$, the anti-pandering equilibrium coexists with an asymmetric "almost efficient" one. If both parties have enough policy motivation $\left(f_{i} \leq f^{a s y m}\right.$ for both $\left.i \in\{1,2\}\right)$, the anti-pandering equilibrium continues to exist but there is an additional coordination problem in the asymmetric equilibrium, as both parties could be the "moderate" one. For some intermediate parameter values, all equilibria can even co-exist. A natural question is thus to understand when we can expect parties to coordinate on which equilibrium.

It is useful to note that there is a clear ranking of the different equilibria from a voters' perspective. First, the anti-pandering equilibrium always dominates the pandering one. The expected utility gain from implementing the anti-pandering policy instead of the pandering one when the two signals are identical is equal to the expected utility loss from doing so when two signals are conflicting. ${ }^{12}$ As signals are more often identical than conflicting, the ranking follows. Second, an asymmetric equilibrium always dominates the anti-pandering one as the policies are identical when signals are conforming, but closer to the center when signals differ.

The coordination problem is however among parties, not voters. Consider first the case when the asymmetric equilibrium does not exist $\left(f_{i}>f^{a s y m}\right.$ for both $\left.i \in\{1,2\}\right)$. When coordinating on an equilibrium, experimental evidence shows that players tradeoff payoff-dominance and risk-dominance (Harsanyi and Selten, 1988 ; Schmidt at al, 2003). As parties have the same probability of being elected in both the anti-pandering and the pandering equilibrium, and the anti-pandering equilibrium yields a better policy, it is payoff-dominant. It is also risk-dominant as, in case the other party adopts the pandering strategy, a party playing the anti-pandering one would be elected more often and implementing a more efficient outcome. We can thus expect parties to coordinate towards the anti-pandering equilibrium whenever the asymmetric one does not exist.

\footnotetext{
${ }^{12}$ It is easy to show that this gain/loss is equal to $\frac{(D-2 D p)^{2}}{8(2(p-1) p+1)^{2}}$.
} 
Second, consider the case when the asymmetric equilibrium exists with only one party in position of being moderate, $\left(f_{i} \leq f^{a s y m}\right.$ for one $\left.i \in\{1,2\}\right)$. As from the previous result, we can already rule out coordination on the pandering equilibrium if it exists. Comparing the asymmetric equilibrium with the anti-pandering one, it is possible to identify a threshold value on the office motivation $f^{p d}=\frac{D^{2}}{4\left(1-2 p+2 p^{2}\right)^{2}}$ such that, for all $f_{i}<f^{p d}$, an asymmetric equilibrium with party $i$ being moderate is Pareto-improving over the anti-pandering equilibrium, and is therefore payoff-dominant. ${ }^{13}$ This asymmetric equilibrium is also risk dominant as the "extreme" party plays the same strategy in the anti-pandering and in the asymmetric equilibrium. We can thus expect that if one and only one party has sufficiently low office motivation, coordination happens on the asymmetric equilibrium.

Third, when the two parties have enough policy motivation to be moderate in an asymmetric equilibrium $\left(f_{i} \leq f^{\text {asym }}\right.$ for both $i \in\{1,2\}$ ), it is clear that unless one party has no office motivation at all $\left(f_{i}=0\right)$ no equilibrium is payoff-dominant as both parties prefer to be the "extreme" one in an asymmetric equilibrium. Moreover, the experimental evidence is not very encouraging towards coordination in such a setting. As shown by Crawford, Gneezy and Rottenstreich (2008), even small payoff-asymmetry can lead to the failure of coordination. To use their terms, there is a tension between "payoff salience" and "label salience". In our setting, this means that even if a party is labeled as moderate we can only expect coordination towards an asymmetric equilibrium if being moderate is never an equilibrium strategy for the other party.

The above discussion suggests that we can expect parties with similar office motivation to behave symmetrically and coordinate on the anti-pandering equilibrium, and sufficiently different parties to behave asymmetrically and coordinate on an almost efficient equilibrium. This implies that there are cases where voters may benefit if the degree of office-motivation of one party (say, party 1) increases, holding $f_{2}$ constant, if it simplifies coordination towards the most efficient asymmetric equilibrium. ${ }^{14}$

\footnotetext{
${ }^{13}$ It always holds that $f^{p d}<f^{a s y m}$, so that there always exists values of $f_{i}$ such that the asymmetric equilibrium exists but is not payoff dominant. Moreover, it is possible to show that when the signal is not too precise $\left(p<\frac{2+\sqrt{2}}{4} \approx 0.85\right)$ the asymmetric equilibrium is payoff-dominant whenever an (almost) efficient asymmetric equilibrium exists $\left(f^{p d}>f^{\text {opt }}\right)$.

${ }^{14}$ Also in Ambrus et al. (2017), voters can benefit from a small amount of office-motivation, while higher levels adversely affect welfare. The underlying mechanisms that lead to this result are, however, different than in our model.
} 


\section{$5 \quad$ Examples}

\subsection{Involvement of Western European countries in the 2003 Iraq war}

On January 29, 2002, in the State of the Union address, US-president George W. Bush declared Iraq, Iran, and North Korea to be an axis of evil. In the following months, the European nations were divided on the issue of whether or not to support the US in a possible war on Iraq, and if so, under what conditions. In line with our model, information clearly played a key role in this policy issue: The US intelligence had apparently presented evidence for a possession of weapons of mass destruction by the regime in Iraq, but the evidence was at least questionable.

We present in Table 1 both the actual involvement and the policy positions of 15 European countries as reported by Hummel (2017). While 9 countries publicly opposed the war, 5 supported it and 1 did not have a clear position. The actual involvement however was broadly of three types. An "extreme" opposition to the war - refusing any involvement or logistical support - was implemented by 4 countries. An "extreme" support - sending combat troops - was implemented by 3 of them. Finally, a "moderate" position of not sending troops but providing logistical support was implemented by 8 countries, among which 5 formally opposed the war, 2 supported it, and 1 had an unclear position.

While not all of those countries had elections at the time of the war, it is striking that their involvement is consistent with the anti-pandering and asymmetric equilibria, except for the case of Portugal. Let us highlights two cases in particular.

In the United Kingdom, Tony Blair, at the time Prime Minister and head of the Labour Party, adopted an extreme position (relative to most other European nations), by promising effectively unconditional support to the US, even in case of a unilateral military attack on Iraq without a new UN-mandate. In line with both the anti-pandering and the asymmetric equilibrium, his "extreme" policy of sending troops to the ground was implemented as the opposition Tory party officially also supported the war. This was clearly not a "pandering" policy as a large majority of his electorate opposed the invasion. While the official party positions were going in the same direction, the issue was very controversial, including inside those parties.

In Germany, in the run-up to the German federal elections (Bundestag), the incumbent chancellor Schröder (Social Democratic Party, SPD), announced in August 2002 that he would not support a possible war on Iraq, not even under a new UN-mandate. However, his policy can still be classified as "moderately opposed," as Germany nevertheless provided logistical support, with several US military bases in the country. His opponent 
Table 1: Level of involvement and official government position on the 2003 Iraq war

\begin{tabular}{|c|c|c|c|c|c|}
\hline Country & $\underline{\text { Involvement }}$ & $\underline{\text { Position }}$ & Country & $\underline{\text { Involvement }}$ & $\underline{\text { Position }}$ \\
\hline$\overline{\text { Austria }}$ & none & against & $\overline{\text { Italy }}$ & logistical & in favour \\
\hline Belgium & logistical & against & Luxembourg & none & against \\
\hline Denmark & military & in favour & Netherlands & logistical & in favour \\
\hline Finland & none & against & Portugal & logistical & uninformative \\
\hline France & logistical & against & Spain & military & in favour \\
\hline Germany & logistical & against & Sweden & none & against \\
\hline Greece & logistical & against & UK & military & in favour \\
\hline Ireland & logistical & against & & & \\
\hline
\end{tabular}

Source: Hummel (2003). We use his classification as follows. We report the involvement in phases 1 and 2 (1: pre-invasion war preparations and 2: The invasion or international war phase). We denote as "logistical" the Level 4 of military involvement ("logistical support"). We denote as "military" the level 1 and 2 of military involvement (combat troops with high (1) and low (2) personal risk). We denote as "none" the level 5 (no war involvement). Official position "in favour" of the war corresponds to level 1 and 2 of the "normative perspective", "against" corresponds to level 4 and 5 , and "unknown" corresponds to level 3.

in the election, Edmund Stoiber (Christian Social Union, CSU) ${ }^{15}$ together with Angela Merkel, ${ }^{16}$ at the time leader of the Christian Democratic Union (CDU, in a permanent alliance with the CSU), by contrast, signaled support for the war, thereby adopting a similar position as Tony Blair. The issue was key in the German elections in 2002, and seen as one of the two main reasons ${ }^{17}$ for the reelection of Schröder and his coalition government with the Green Party (Pulzer, 2003). Only a few weeks before the election, the polls still pointed towards a change in the government. The outcome of the election that took place in Germany in 2002, seems to be in line with the asymmetric equilibrium in our model: while the CDU adopted an extreme position, Schröder's party adopted a more moderate one on the other side of the policy spectrum, for which case our model predicts the moderate party to win the election.

\subsection{Climate policy}

The current debate about climate change revolves around the policy response to a forthcoming environmental catastrophe, corresponding to the presence of a threshold or 'tipping point' in the climate system (see for instance Barnosky et al, 2012). Comprehensive predictions are regularly made by the Intergovernmental Panel on Climate Change (IPCC). As the IPCC is in the position of "natural monopoly" (Tol, 2011), the political question is, thus, primarily whether or not to trust the current state of the scientific literature as summarized by the panel. This question constitutes a typical example where ideological biases of experts may hinder the precision of the information transmitted, so

\footnotetext{
15 "Stoiber vows to back U.S. on Iraq," cnn.com, September 19, 2002

16 "Schroeder Doesn't Speak for All Germans," Angela Merkel, The Washington Post, February 20, 2003.

${ }^{17}$ The other was the flooding in the Danube and Elbe valleys in mid-August, in which Schröder "displayed almost perfect crisis-management." (Pulzer, 2003, p.156)
} 
that it is reasonable to model the question as binary. ${ }^{18}$ The action space is however not binary, as the abatement of emissions is a continuous choice in the form of emission targets. Given the complexity of the question, there is evidence that voters extract information about the state of the world from parties' publicly stated opinions or policy platforms (see for instance Guber, 2013; Hornsey et al., 2016). Regarding ideology, Ansolabehere and Konisky (2014) show that Americans are more pragmatic than ideological in their opinions about energy alternatives and pollution. ${ }^{19}$

In most countries, political parties take either moderate or pro-active policy positions recognizing the existence of climate change. In a recent study carried out at the COP21 climate conference, Bosetti et al (2017, p.187) find that many government negotiators take "moderate" views of the risk posed by climate change, more distant from the scientific consensus than the non-negotiators. ${ }^{20}$ In some countries however, and notably the US, one political party campaigns on a "climate-skeptical" position. ${ }^{21}$ The co-existence of many moderate and pro-active elected parties with very few climate-skeptical ones is consistent with at least some information being transmitted in elections, either through anti-pandering or asymmetric equilibria.

\subsection{Nuclear energy in Germany}

The debate revolving around the use of nuclear electricity is a recurrent topic in German politics. Understanding the cost-efficiency and potentially dangerous nature of nuclear power stations requires gathering a lot of information, that voters are likely to take in a digested form from political parties. While the desirability of nuclear energy is largely a binary question, the share of nuclear in the energy mix is a continuous decision.

In the early 2000s, the Christian Democratic Party (CDU) favored a continuation of the usage of atomic power, the Social Democrats (SPD), in alliance with the Green Party, pushed towards a nuclear phase-out within a limited time frame. In 2002, under chancellor Schröder and a coalition-government of SPD and the Green Party, moderate phase-out became Germany's official policy, based on a consensus reached with the leading electricity companies requiring a complete phase-out until the year 2022. After chancellor Merkel

\footnotetext{
${ }^{18}$ See for instance Lupia (2013) on the difficulties to communicate science in a politicized environment. The question is generally represented as "adhering to the scientific consensus on man-made climate change" both in the media and in research (see for instance Cook et al., 2016).

${ }^{19}$ Moreover, while the approach may vary, ambitious pollution abatements do not have to be ideologically left-leaning, a prominent example being the first large tradable emission permit market implemented in 1990 under the Bush administration (Joskow, Schmalensee, and Bailey 1998).

${ }^{20}$ The question asked to negotiators relates to their view on the scientific evidence and not on the way to achieve international cooperation, a question outside the scope of our model.

21 "The United Nations' Intergovernmental Panel on Climate Change is a political mechanism, not an unbiased scientific institution. Its unreliability is reflected in its intolerance toward scientists and others who dissent from its orthodoxy. We will evaluate its recommendations accordingly," US Republican Party official platform 2016 (p.20).
} 
took over, and the CDU was the leading party, the phase-out policy was abandoned, granting substantially longer usage of existing nuclear power plants to the electricity providers. Yet, after the Fukushima Daiichi nuclear disaster, the CDU under Merkel changed its position radically. In 2011, Merkel indeed committed to a much faster nuclear phase-out, without cooperation with the electricity companies, with eight reactors shut down immediately. ${ }^{22}$

In that context, one party (the SPD) seems to keep a "moderate" position over time, while the other (the CDU, ideologically a rather centrist party) is much more responsive to the information it receives. This pattern is consistent with the asymmetric equilibrium we identify, consistent with the behavior of those parties in the example of the Iraq war described above, and consistent with the fact that the CDU is more often in government than the SPD.

\section{Conclusion}

In a complex world, even interested voters cannot be well-informed about every conceivable policy dimension. Hence, they have to rely on representatives and their experts who collect information for them. Parties can then try to signal their private information to the voters via their platform choices, and voters elect the party that offers a more attractive platform, given their updated beliefs.

Using a parsimonious setup, we demonstrate that when at least one party cares not only about about holding office but also about the efficiency of the implemented policy, representative democracy may well be able to convey the private information of both parties to the voters. While in a symmetric equilibrium, the outcome then exhibits antipandering, that is, platform choices are more extreme than would be socially desirable, relaxing the symmetry assumption leads to a richer set of outcomes that can be implemented. In particular, there exists an asymmetric equilibrium in which parties truthfully reveal their private information, and the implemented outcomes are (almost) first-best for any realization of the two parties' signals. In this equilibrium, one party adopts more extreme policy positions: it follows its true signal but behaves as if it had received two signals with identical contents. The other party adopts a moderate position: close to the "neutral policy", voters' preferred policy when signals are conflicting, just distorted enough to still convey its signal credibly to the voters.

An interesting extension of our model would be to analyze whether asymmetric equilibria, similar to the one characterized in this paper, may exist also under a continuous state and signal space, in a setting similar to the one of Ambrus et al. (2017). Furthermore, it is not obvious how the equilibrium outcome would change if parties have biased

\footnotetext{
${ }^{22}$ Source: http://www.world-nuclear.org/, visited March 5, 2018.
} 
preferences. We leave these challenges as starting points for future research.

\section{Appendix A: Equilibrium refinement}

Here we provide a formal definition of the equilibrium refinement (informally discussed in the main text), applying the intuitive criterion of Cho and Kreps (1987).

Consider a PBE $\left(x_{1}^{*}(\cdot), x_{2}^{*}(\cdot), \sigma^{*}(\cdot, \cdot)\right)$, combined with voters' beliefs that assign a probability of $\mu\left(x_{1}, x_{2}\right)$ to the state $W=G$, conditional on observing actions $x_{1}, x_{2} \in \mathbb{X}$. The resulting payoff of party $1^{23}$ when observing signal $s_{1}$ is

$$
U_{1}^{*}\left(s_{1}\right) \equiv E_{s_{2} \mid s_{1}} U_{1}\left(s_{1}, s_{2}, x_{1}^{*}\left(s_{1}\right), x_{2}^{*}\left(s_{2}\right), \sigma^{*}\left(x_{1}^{*}\left(s_{1}\right), x_{2}^{*}\left(s_{2}\right)\right)\right)
$$

We say that action (policy platform choice) $x_{1}$ is equilibrium dominated for signal $s_{1}$ if there is no voters' belief such that party 1 would increase its payoff by playing $x_{1}$.

Formally,

$$
U_{1}^{*}\left(s_{1}\right) \geq E_{s_{2} \mid s_{1}} \max _{\sigma \in R^{*}\left(x_{1}, x_{2}^{*}\left(s_{2}\right)\right)} U_{1}\left(s_{1}, s_{2}, x_{1}, x_{2}^{*}\left(s_{2}\right), \sigma\right),
$$

where $R^{*}\left(x_{1}, x_{2}\right) \in[0,1]$ is the set of possible equilibrium responses $\sigma$ of the voters that can arise after actions $x_{1}$ and $x_{2}=x_{2}^{*}(\cdot)$ are observed, for some belief function $\mu\left(x_{1}, x_{2}^{*}\left(s_{2}\right)\right)$ conditional on observing $x_{1}$. In a PBE the belief function is constrained in the sense that voters never assign a probability lower than zero or higher than one to player 1 having observed a good signal, $\operatorname{Pr}\left[s_{1}=g \mid x_{1}\right] \in[0,1]$. If $x_{2}^{*}$ is a fully revealing strategy, this constraint translates into

$$
\begin{aligned}
& \mu\left(x_{1}, x_{2}^{*}(b)\right) \in\left[\beta_{b b}, \beta_{b g}\right], \\
& \mu\left(x_{1}, x_{2}^{*}(g)\right) \in\left[\beta_{b g}, \beta_{g g}\right] .
\end{aligned}
$$

If $x_{2}^{*}$ is a non-revealing strategy,

$$
\mu\left(x_{1}, x_{2}^{*}(.)\right) \in\left[\beta_{b}, \beta_{g}\right]
$$

An important property of $R^{*}\left(x_{1}, x_{2}^{*}\left(s_{2}\right)\right)$ is that voters' best response $\sigma$ (given $x_{1}$ and $\left.x_{2}^{*}\left(s_{2}\right)\right)$, as a function of $\mu\left(x_{1}, x_{2}^{*}\right)$, is monotonic in $\mu$. This follows from the ordering of $x_{1}$ and $x_{2}^{*}\left(s_{2}\right)$, which (for a given realization of $s_{2}$ ) either fulfills: $x_{1}>x_{2}^{*}, x_{1}<x_{2}^{*}$, or $x_{1}=x_{2}^{*}$. This ordering is clearly not affected by $\mu$. Therefore, $\sigma$ as a function of $\mu$ (for a given realization of $s_{2}$ ), is either (weakly) increasing or (weakly) decreasing, with at most one discontinuity. If $x_{1}<x_{2}^{*}$, then the equilibrium probability $\sigma\left(x_{1}, x_{2}^{*}\right)$ that voters elect party 1 is increasing in the belief that the state of the world is good $\mu$, while it is

\footnotetext{
${ }^{23}$ We show definitions here only for party 1 ; for party 2 , corresponding definitions apply but are not shown here for the sake of brevity.
} 
decreasing if $x_{1}>x_{2}^{*}$. Moreover, party 1 does not care for which beliefs of the voters it is elected, since voters' belief does not enter directly its payoff function (only indirectly via $\sigma$ ). Hence, when considering whether a deviation to $x_{1}$ is profitable for some beliefs, it is enough to verify whether it is profitable for extreme beliefs $\hat{s}_{1} \in\{g, b\}$.

Let $\mathbb{X}_{1}^{-}=\left\{x_{1} \in \mathbb{X}\right.$ but $\left.x_{1} \notin\left\{x_{1}^{*}(g), x_{1}^{*}(b)\right\}\right\}$ be the set of off-path choices of $x_{1}$. Now define for each $x_{1}^{\prime} \in \mathbb{X}_{1}^{-}$the set $S_{1}^{*}\left(x_{1}^{\prime}\right)=\left\{s_{1}\right.$ : condition (17) does not hold $\}$. Note that $S_{1}^{*}\left(x_{1}^{\prime}\right) \in\{\{g, b\},\{g\},\{b\}, \varnothing\}$. Intuitively, if $S_{1}^{*}\left(x_{1}^{\prime}\right)=\{g, b\}$ then party 1 would deviate to action $x_{1}^{\prime}$ for each possible realization of its signal for some belief. If $S_{1}^{*}\left(x_{1}^{\prime}\right)=\{g\}$ then party 1 would never deviate to action $x_{1}^{\prime}$ when $s_{1}=b$, for any belief. If $S_{1}^{*}\left(x_{1}^{\prime}\right)=\varnothing$ then party 1 would never deviate to $x_{1}^{\prime}$, no matter what voters infer about $s_{1}$, and what signal party 1 actually obtained. Note that in all these cases, we are assuming that voters always respond optimally to their beliefs when choosing $\sigma$, taking party 2's policy platform into consideration when forming their belief $\mu\left(x_{1}^{\prime}, x_{2}\right)$.

Definition 2. A PBE fulfills the intuitive criterion if for all actions $x_{1}^{\prime} \in \mathbb{X}_{1}^{-}$, it holds that

(i) if $S_{1}^{*}\left(x_{1}^{\prime}\right)=\{g\}$ then $\hat{s}_{1}\left(x_{1}^{\prime}\right)=g$,

(ii) if $S_{1}^{*}\left(x_{1}^{\prime}\right)=\{b\}$ then $\hat{s}_{1}\left(x_{1}^{\prime}\right)=b$.

To verify whether a unilateral deviation from a candidate equilibrium can be profitable under the intuitive criterion, the procedure is as follows. First, we need to verify whether we are in case (i) or (ii), and in order to do so it is enough to consider whether a deviation to $x_{1}^{\prime}$ is profitable for extreme' beliefs $\hat{s}_{i} \in\{g, b\}$. Second, in the case $S_{1}^{*}\left(x_{1}^{\prime}\right)=\{g, b\}$ one can assign any weight on player 1 having observed $s_{1}=g$, as long as $\mu\left(x_{1}, x_{2}^{*}\right)$ satisfies conditions (18), (19) and (20). The case $S_{1}^{*}\left(x_{1}^{\prime}\right)=\varnothing$ is trivial as such a deviation is by definition never profitable.

\section{Appendix B: Proofs}

Proof of Lemma 1. 1. Straightforward from our definition of $x_{g g}^{*}, x_{g b}^{*}$ and $x_{b b}^{*}$.

2. If strategies are skewed $x_{b} \neq D-x_{g}$ then one platform yields strictly higher expected utility when signals are conflicting. Consider first the case in which policy $x_{g}$ is chosen only when signals are identical $s_{1}=s_{2}=g$. The maximization problem is

$$
\max _{x_{g}, x_{b}} \operatorname{Pr}\left(s_{1}=s_{2}=g\right) u\left(\beta_{g g}, x_{g}\right)+\operatorname{Pr}\left(s_{1} \neq s_{2}\right) u\left(\beta_{g b}, x_{b}\right)+\operatorname{Pr}\left(s_{1}=s_{2}=b\right) u\left(\beta_{b b}, x_{b}\right) .
$$


As $x_{g g}^{*}$ is optimal for $s_{1}=s_{2}=g$ it is straightforward that $x_{g}=x_{g g}^{*}$. We also find $x_{b}=\tilde{x}_{b}=D \frac{(2-p) p}{1-2(1-p) p} \in\left(D / 2, x_{b}^{*}\right)$. A similar result can be reached with $x_{b b}^{*}$ chosen only when signals are identical $s_{1}=s_{2}=b$, as the problem is symmetric.

3. Given the parties' strategies $x_{i}(g)=x_{g}$ and $x_{i}(b)=x_{b}$ with $x_{b}=D-x_{g}$ and $x_{g}<D / 2$, voters' expected utility is

$$
-\frac{x_{g}^{2}}{4}-\frac{x_{b}^{2}}{4}-\frac{D}{2}\left[(1-p)^{2}\left(1-x_{g}\right)+p^{2}\left(1-x_{b}\right)+p(1-p)\left(\left(1-x_{g}\right)+\left(1-x_{b}\right)\right)\right],
$$

where we have used the assumption that voters choose $x_{g}$ resp. $x_{b}$ with a probability of $1 / 2$ when platforms differ, and the probabilities: $\operatorname{Pr}[W=B]=1 / 2, \operatorname{Pr}\left[s_{1}=\right.$ $\left.s_{2}=g \mid W=B\right]=(1-p)^{2}, \operatorname{Pr}\left[s_{1}=s_{2}=b \mid W=B\right]=p^{2}$, as well as $\operatorname{Pr}\left[s_{i}=g, s_{-i}=\right.$ $b \mid W=B]=2 p(1-p)$. The maximization over $x_{g}$ and $x_{b}$ then yields $x_{g}=x_{g}^{*}$ and $x_{b}=x_{b}^{*}$. As $x_{g}^{*}$ and $x_{b}^{*}$ yield identical utility when signals are conflicting, taking the probability of one party being elected under conflicting signals to 1 does not affect aggregate welfare. As conditional on one of the two probabilities of being elected under conflicting signals, we have shown in 2 . that skewed signals are optimal, we know that the restriction $x_{b}=D-x_{g}$ yields lower expected welfare.

Proof of Proposition 1. Given parties' equilibrium strategies, when $s_{1}=s_{2}=g$ or when $s_{1}=s_{2}=b$ then party 1 wins the election with probability 1 , whereas when signals are conflicting party 2 wins with probability 1 . If party 1 receives a good signal, its expected payoff in equilibrium is

$$
\pi\left[u\left(\beta_{g g}, x_{g g}^{*}\right)+f_{1}\right]+(1-\pi) u(1 / 2, D / 2-\alpha) .
$$

If party 2 receives a good signal, its expected payoff in equilibrium is

$$
\pi u\left(\beta_{g g}, x_{g g}^{*}\right)+(1-\pi)\left[u(1 / 2, D / 2-\alpha)+f_{2}\right]
$$

where we use the fact that $u(1 / 2, D / 2-\alpha)=u(1 / 2, D / 2+\alpha)$. Now consider possible deviations satisfying the intuitive criterion.

Party 2: Suppose $s_{2}=g$.

Claim (i) A deviation to $x_{2}^{\prime}=D / 2+\alpha$ is not profitable. If this deviation induces voters to draw an incorrect inference about party 2's signal $\left(\hat{s}_{2}\left(x_{2}^{\prime}\right)=b\right)$, party 2's winning probability is raised. The implemented policy is, however, less efficient than under party 2 's equilibrium strategy. Comparing party 2's expected welfare under the equilibrium 
strategy (see above) with its welfare under the deviation:

$$
\pi\left[u\left(\beta_{g g}, D / 2+\alpha\right)+f_{2}\right]+(1-\pi) u\left(1 / 2, x_{b b}^{*}\right)
$$

we obtain a lower bound for the value $\alpha,{ }^{24}$ with $\frac{d \alpha}{d f_{2}}>0$. Define $f^{o p t}=\frac{D^{2}}{8\left(1-2 p+2 p^{2}\right)^{2}}$ as the threshold value of $f_{2}$ such that party 2 is indifferent between deviating or not when $\alpha=0$. When $f_{2}<f^{o p t}$, the constraint is not binding so that the lower bound for $\alpha$ is negative. If $f_{2} \leq f^{o p t}$, we can set $\alpha$ arbitrarily small, but positive so that party 2 can still convey its signal to the voters, while implementing an (almost) efficient policy (in case this party is elected).

(ii) A deviation to $x_{2}^{\prime} \in\left(x_{g g}^{*}, D / 2-\alpha\right)$ is not profitable. The deviation policy is too distorted to be a profitable deviation after observing $s_{2}=b$ (see (i)). Hence, the intuitive criterion requires that if a deviation to $x_{2}^{\prime}$ is profitable for some beliefs after observing $s_{2}=g$, voters infer with probability 1 that party 2 observed signal $g$. However, for $\hat{s}_{2}\left(x_{2}^{\prime}\right)=g$, the deviation is not profitable as party 2 would get elected with the same probability as under the equilibrium policy (i.e., only when signals are conflicting), but the implemented policy is then inferior.

(iii) A deviation to $x_{2}^{\prime \prime} \in\left(D / 2+\alpha, x_{b b}^{*}\right)$ is not profitable, because it leads to a lower payoff than a deviation to $x_{2}^{\prime}=D / 2+\alpha$ (ruled out in (i)).

(iv) A deviation to $x_{2}^{\prime} \in(D / 2-\alpha, D / 2+\alpha)$ is not profitable if $f_{2}<f^{a s y m}$. For a deviation to a policy in this range, there always exists a belief of voters about $s_{2}$ such that the deviation is profitable, under both signal realizations $\left(s_{2}=g\right.$ and $\left.s_{2}=b\right)$, as follows from our discussion above (see case (i)).

We want to show that there exist out-of equilibrium beliefs satisfying the intuitive criterion such that party 2 deviating to $x_{2}^{\prime} \in(D / 2-\alpha, D / 2+\alpha)$ is never elected when party 1 plays its equilibrium strategy, regardless of $s_{1}$, for all $D / 2-\alpha>x_{g g}^{*}$ and $D / 2+\alpha<x_{b b}^{*}$ with $\alpha$ defined above (see just below (22)). As there exist some beliefs such that a deviation to any $x_{2}^{\prime} \in(D / 2-\alpha, D / 2+\alpha)$ is profitable after observing $s_{2}=g$ or $s_{2}=b$, using the intuitive criterion, any belief that puts weakly positive probability on each signal upon observing $x_{2}^{\prime}$ is acceptable. This translates into the following constraints (see Appendix A):

$$
\begin{aligned}
& \mu\left(x_{1}^{*}(g), x_{2}^{\prime}\right) \in\left[\beta_{b g}, \beta_{g g}\right] \\
& \mu\left(x_{1}^{*}(b), x_{2}^{\prime}\right) \in\left[\beta_{b b}, \beta_{b g}\right] .
\end{aligned}
$$

For a deviation to $x_{2}^{\prime} \in(D / 2-\alpha, D / 2+\alpha)$ never to be profitable, out of equilibrium

$$
{ }^{24} \alpha=\frac{2 \sqrt{\left(D^{2}(p-1)^{2} p^{2}+2 f_{2}\left(-4 p^{3}+6 p^{2}-4 p+1\right)^{2}\right)}-D\left(2 p^{2}-2 p+1\right)}{2(2 p-1)\left(2 p^{2}-2 p+1\right)} .
$$


beliefs must satisfy simultaneously

$$
\begin{aligned}
& u\left(\mu\left(x_{1}^{*}(g), x_{2}^{\prime}\right), x_{g g}^{*}\right)>u\left(\mu\left(x_{1}^{*}(g), x_{2}^{\prime}\right), x_{2}^{\prime}\right) \\
& u\left(\mu\left(x_{1}^{*}(b), x_{2}^{\prime}\right), x_{b b}^{*}\right)>u\left(\mu\left(x_{1}^{*}(b), x_{2}^{\prime}\right), x_{2}^{\prime}\right) .
\end{aligned}
$$

Where (25) corresponds to player 2 not being elected by choosing $x_{2}^{\prime}$ when player 1 observed a good signal, and (26) to player 2 not being elected by choosing $x_{2}^{\prime}$ when player 1 observed a bad signal. The beliefs $\mu\left(x_{1}^{*}(g), x_{2}^{\prime}\right)=\beta_{g g}$ and $\mu\left(x_{1}^{*}(b), x_{2}^{\prime}\right)=\beta_{b b}$ satisfy conditions (23) and (24). Replacing in (25) and (26) we obtain

$$
\begin{aligned}
& u\left(\beta_{g g}, x_{g g}^{*}\right)>u\left(\beta_{g g}, x_{2}^{\prime}\right) \\
& u\left(\beta_{b b}, x_{b b}^{*}\right)>u\left(\beta_{b b}, x_{2}^{\prime}\right) .
\end{aligned}
$$

By our definition of $x_{g g}^{*}$, the only value such that inequality (27) is not satisfied is $x_{2}=x_{g g}^{*}$ and the only value such that inequality $(28)$ is not satisfied is $x_{2}=x_{b b}^{*}$. Thus, there exists out-of equilibrium beliefs satisfying the intuitive criterion such that party 2 deviating to $x_{2}^{\prime} \in(D / 2-\alpha, D / 2+\alpha)$ is never elected when party 1 plays its equilibrium strategy, for all $D / 2-\alpha>x_{g g}^{*}$ and $D / 2+\alpha<x_{b b}^{*}$. Note that this is a general result, that we also use in subsequent propositions: it is always possible to construct out-of-equilibrium beliefs for a policy $x \in\left(x_{g g}^{*}, x_{b b}^{*}\right)$ putting weakly positive weight on each possible signal such that a party offering policy $x$ against a party playing anti-pandering equilibrium strategies never wins the election. Using the value of $\alpha$ found above, we can rewrite the conditions $D / 2-\alpha>x_{g g}^{*}$ and $D / 2+\alpha<x_{b b}^{*}$ in terms of $f_{2}$ as

$$
f_{2}<f^{a s y m}=\frac{D^{2}}{2\left(2 p^{2}-2 p+1\right)}
$$

(v) A deviation to $x_{2}^{\prime}=x_{g g}^{*}$ or to $x_{2}^{\prime}=x_{b b}^{*}$ is not profitable. To rule out this type of deviation, we assume (see Section 3.2) that voters elect party 1 when this party chooses one of its equilibrium policy platforms, while party 2 chooses this type of deviation (as parties are clearly identifiable). This type of deviation is, thus, never profitable, irrespective of voters' belief about $s_{2}$.

(vi) A deviation to $x_{2}^{\prime}<x_{g g}^{*}$ or $x_{2}^{\prime}>x_{b b}^{*}$ is not profitable. This claim is always true as voters would never elect such a party after observing at most two signals when the other party plays its equilibrium strategy (see Section 2.2).

Party 1: Suppose $s_{1}=g$. (The argument for the case where $s_{1}=b$ follows analogously.) A deviation by party 1 can only be profitable if (i) it strictly raises its probability of being elected $(\sigma)$, and/or (ii) the quality of the implemented policy is (in expectation) raised due to the deviation. 
(i) It is straightforward to verify that there exists no deviation for party 1 that guarantees this party to be elected both when $s_{2}=g$ and $s_{2}=b$ : irrespective of what voters infer about the contents of party 1's signal when observing the deviation, it always holds that party 2's equilibrium policy is (weakly) closer to voters' most preferred policy (given their belief) either under $s_{2}=g$ or under $s_{2}=b$ than party 1's deviation platform. In the knife-edge case where voters infer $\hat{s}_{1}\left(x_{1}^{\prime}\right)=g\left(\hat{s}_{1}\left(x_{1}^{\prime \prime}\right)=b\right)$ when party 1 deviates to $x_{1}^{\prime}=D / 2-\alpha\left(x_{1}^{\prime \prime}=D / 2+\alpha\right)$, voters are indifferent between parties' platforms under both realizations of $s_{2}$. In this case, we can simply assume that voters elect the party that did not deviate (see Sections 3.2 and 4.1). Since, in equilibrium, party 1 is already elected with certainty under party 2's most likely signal realization (given $s_{1}=g$ ), a deviation can only (weakly) reduce $\sigma$.

(ii) This is impossible to achieve because party 1's equilibrium policy is already optimal when signals are conforming; if party 1 were purely policy-motivated, its best (candidate) deviation would be to offer $x_{1}^{\prime}=D / 2-\epsilon$, where $\epsilon$ is an arbitrarily small positive number (just large enough so that voters can still distinguish this policy from $D / 2)$ when $s_{1}=g$, resp. $x_{1}^{\prime \prime}=D / 2+\epsilon$ when $s_{1}=b$. This way, party 1 could still convey its signal to the voters, and (assuming voters believe in this) party 1 would get elected whenever signals are conflicting, in which case the welfare-optimal (neutral) policy would be offered (distorted only by $\epsilon$, that is assumed infinitesimally small). It is however possible to construct out-of-equilibrium beliefs satisfying the intuitive criterion and ruling out such a deviation. Every such deviation that is profitable under some beliefs after observing a given signal is also profitable for some beliefs after observing the other signal. The intuitive criterion therefore does not rule out any belief on the signal observed by party 1 . Hence, for any equilibrium policy of player 2 and any such candidate deviation to $x_{1}^{\prime}$ by party 1 , the intuitive criterion only yield the following constraints

$$
\begin{aligned}
& \mu\left(x_{1}^{\prime}, x_{2}^{*}(g)\right) \in\left[\beta_{b g}, \beta_{g g}\right] \\
& \mu\left(x_{1}^{\prime}, x_{2}^{*}(b)\right) \in\left[\beta_{b b}, \beta_{b g}\right] .
\end{aligned}
$$

As $x_{g g}^{*}<x_{2}^{*}(g)<x_{b g}^{*}<x_{2}^{*}(b)<x_{b b}^{*}$, it is possible to construct $\mu\left(x_{1}^{\prime}, x_{2}^{*}(g)\right)$ such that

$$
x_{2}^{*}(g)=\arg \max _{x} u\left(\mu\left(x_{1}^{\prime}, x_{2}^{*}(g)\right), x\right) .
$$

Indeed, as $x_{2}^{*}(g)$ is located between $x_{g g}^{*}$ and $D / 2$, we can always find $\mu\left(x^{\prime}, x_{2}^{*}(g)\right)$ such that $x_{2}^{*}(g)$ is the optimal policy for this $\mu$. Similarly $\mu\left(x_{1}^{\prime}, x_{2}^{*}(b)\right)$ such that $x_{2}^{*}(b)=$ $\arg \max _{x} u\left(\mu\left(x_{1}^{\prime}, x_{2}^{*}(b)\right), x\right)$ and voters always prefer party 2 .

Hence, as long as $D / 2-\alpha>x_{g g}^{*}$ and $D / 2+\alpha<x_{b b}^{*}$, it is possible to construct out-of-equilibrium beliefs sustaining the equilibrium. The condition for an asymmetric equilibrium to exist satisfying the intuitive criterion therefore corresponds to $D / 2-\alpha>$ 
$x_{g g}^{*}\left(\right.$ or $\left.D / 2+\alpha<x_{b b}^{*}\right), f<f^{a s y m}$.

Proof of Lemma 2. We first show that there exists a profitable deviation if at least one platform is "very extreme" $x \notin\left[x_{g g}^{*}, x_{b b}^{*}\right]$. Suppose $x_{g}<x_{g g}^{*}$. (The case where $x_{b}>x_{b b}^{*}$ follows analogously.) When $s_{1}=g$, then for all $\hat{s}_{1}\left(x_{g g}^{*}\right) \in\{g, b\}$, a deviation by party 1 to $x_{g g}^{*}$ increases both the probability of being elected and the quality of the expected policy. With probability $\pi, s_{2}=g$, and it always holds that $\sigma\left(x_{g g}^{*}, x_{g}\right)=1$ and $u\left(\beta_{g g}, x_{g}\right)<$ $u\left(\beta_{g g}, x_{g g}^{*}\right)$. With probability $1-\pi, s_{2}=b$, and it always holds that $\sigma\left(x_{g g}^{*}, x_{b}\right) \geq \sigma\left(x_{g}, x_{b}\right)$. It is also easy to verify that if $\sigma\left(x_{g g}^{*}, x_{b}\right)>0$, then $u\left(\beta_{g b}, x_{b}\right)<u\left(\beta_{g b}, x_{g g}^{*}\right)$. The same reasoning holds for $x_{b}>x_{b b}^{*}$.

Second, consider symmetric strategies with $x_{g}>D-x_{b}$, and $x_{b} \neq x_{b b}^{*}$, so that $u\left(\beta_{g b}, x_{g}\right)>u\left(\beta_{g b}, x_{b}\right)$, and $\sigma\left(x_{g}, x_{b}\right)=1$. Under the proposed equilibrium strategy, the expected utility of party 1 after receiving a good resp. bad signal is

$$
\begin{aligned}
& U_{1}^{*}(g)=\pi\left(u\left(\beta_{g g}, x_{g}\right)+\frac{f_{1}}{2}\right)+(1-\pi)\left(u\left(\beta_{g b}, x_{g}\right)+f_{1}\right), \\
& U_{1}^{*}(b)=\pi\left(u\left(\beta_{b b}, x_{b}\right)+\frac{f_{1}}{2}\right)+(1-\pi)\left(u\left(\beta_{g b}, x_{g}\right)\right) .
\end{aligned}
$$

We want to show that $x_{b b}^{*}$ is a profitable deviation after observing $s_{1}=b$ under the only belief satisfying the intuitive criterion $\hat{s}_{1}\left(x_{b b}^{*}\right)=b$. For this, we need to show that (i) $x_{b b}^{*}$ is not a profitable deviation for any belief after observing $s_{1}=g$, and (ii) $x_{b b}^{*}$ is a profitable deviation for $\hat{s}_{1}\left(x_{b b}^{*}\right)=b$ after observing $s_{1}=b$.

For claim (i), it is enough to study $\hat{s}_{1}\left(x_{b b}^{*}\right)=b$ to characterize all profitable deviations to $x_{b b}^{*}$ when $s_{1}=g$. Indeed, player 1 is never elected if $s_{2}=g\left(\sigma\left(x_{b b}^{*}, x_{g}\right)=0\right.$ and all $\hat{s}_{1}\left(x_{b b}^{*}\right)$ ), and always elected and implementing the optimal strategy if $s_{2}=b$ for $\hat{s}_{1}\left(x_{b b}^{*}\right)=b$.

The expected utility under the suggested deviation is

$$
U_{1}\left(x_{b b}^{*} \mid s_{1}=g, \hat{s}_{1}=b\right)=\pi u\left(\beta_{g g}, x_{g}\right)+(1-\pi)\left(u\left(\beta_{g b}, x_{b b}^{*}\right)+f_{1}\right)<U_{1}^{*}(g),
$$

as $u\left(\beta_{g b}, x_{b b}^{*}\right)<u\left(\beta_{g b}, x_{g}\right)$.

For claim (ii), the expected utility under the suggested deviation is

$$
U_{1}\left(x_{b b}^{*} \mid s_{1}=b, \hat{s}_{1}=b\right)=\pi\left(u\left(\beta_{b b}, x_{b b}^{*}\right)+f_{1}\right)+(1-\pi) u\left(\beta_{g b}, x_{g}\right)>U_{1}^{*}(b) .
$$

Third, consider symmetric strategies with $x_{g}>D-x_{b}$, and $x_{b}=x_{b b}^{*}$, so that $u\left(\beta_{g b}, x_{g}\right)>u\left(\beta_{g b}, x_{b}\right)$, and $\sigma\left(x_{g}, x_{b}\right)=1$. Under the proposed equilibrium strategy, the expected utility of party 1 is as in the second part of the proof, replacing $x_{b}=x_{b b}^{*}$. In this case, $x_{b b}^{*}$ is not a deviation anymore. It is however possible to show that such 
an equilibrium never exists sustained by out-of-equilibrium beliefs satisfying the intuitive criterion (see online appendix).

Finally, consider symmetric strategies with $x_{g}=D-x_{b}$, so that both $x_{g} \neq x_{g g}^{*}$ and $x_{b} \neq x_{b b}^{*}$.

Under the equilibrium strategy, the expected utility of party 1 after receiving a good resp. bad signal is

$$
\begin{aligned}
& U_{1}^{*}(g)=\pi u\left(\beta_{g g}, x_{g}\right)+(1-\pi) u\left(\beta_{g b}, x_{g}\right)+\frac{f_{1}}{2}, \\
& U_{1}^{*}(b)=\pi u\left(\beta_{b b}, x_{b}\right)+(1-\pi) u\left(\beta_{g b}, x_{g}\right)+\frac{f_{1}}{2} .
\end{aligned}
$$

We want to show that $x_{g g}^{*}$ is a profitable deviation after observing $s_{1}=g$ under the only belief satisfying the intuitive criterion $\hat{s}_{1}\left(x_{g g}^{*}\right)=g$. For this, we need to show that (i) $x_{g g}^{*}$ is not a profitable deviation for any belief after observing $s_{1}=b$, and (ii) $x_{g g}^{*}$ is a profitable deviation for $\hat{s}_{1}\left(x_{g g}^{*}\right)=g$ after observing $s_{1}=g$. For (i), for reasons similar as in the second part of the proof, it is enough to consider $\hat{s}_{1}\left(x_{g g}^{*}\right)=g$. Under the assumed beliefs, $\sigma\left(x_{g g}^{*}, x_{b}\right)=0$ and $\sigma\left(x_{g g}^{*}, x_{g}\right)=1$. This yields expected payoff

$$
U_{1}\left(x_{g g}^{*} \mid s_{1}=b, \hat{s}_{1}=g\right)=\pi\left(u\left(\beta_{b b}, x_{b}\right)\right)+(1-\pi)\left(u\left(\beta_{g b}, x_{g g}^{*}\right)+f_{1}\right)<U_{1}^{*}(b) .
$$

For (ii), the expected payoff under the proposed deviation is

$$
U_{1}\left(x_{g g}^{*} \mid s_{1}=g, \hat{s}_{1}=g\right)=\pi\left(u\left(\beta_{g g}, x_{g g}^{*}\right)+f_{1}\right)+(1-\pi) u\left(\beta_{g b}, x_{b}\right)>U_{1}^{*}(g) .
$$

This completes the proof.

Proof of Proposition 2. We study deviations by party 1 after observing $s_{1}=g$, assuming equilibrium behavior for party 2 . The other case (deviations after observing $s_{1}=b$ ), and deviations by party 2 , follow analogously by symmetry.

Claim (i) A deviation to some "extreme" policy $x_{1}<x_{g g}^{*}$ or $x_{1}>x_{b b}^{*}$ is never profitable. This claim is always true as voters would never elect such a party after observing at most two signals when the other party plays its equilibrium strategy.

(ii) There exists out-of-equilibrium beliefs satisfying the intuitive criterion such that a deviation to some "moderate" policy $x \in\left(x_{g g}^{*}, x_{b b}^{*}\right)$ after observing $s_{1}=g$ is never profitable if it is profitable for some beliefs after observing $s_{1}=b$. We have shown in the proof of Proposition 1 (iv) that it is always possible to construct out-of-equilibrium beliefs for a policy $x \in\left(x_{g g}^{*}, x_{b b}^{*}\right)$ putting weakly positive weight on each possible signal such that a party offering policy $x$ against a party playing anti-pandering equilibrium strategies never wins the election. 
(iii) There is no profitable deviation to some $x^{\prime} \neq x_{g g}^{*}$ after observing $s_{1}=g$ if $x^{\prime}$ is not a profitable deviation after observing $s_{1}=b$ for any beliefs. The intuitive criterion requires that for such a deviation, out-of-equilibrium beliefs must be $\hat{s}_{1}\left(x^{\prime}\right)=g$. Upon observing $s_{1}=g$, if party 2 plays its equilibrium strategy, the policy $x$ that maximises the probability for party 1 to be elected by voters who believe $\hat{s}_{1}(x)=g$ is $x_{g g}^{*}$. A deviation to $x_{1} \neq x_{g g}^{*}$ thus never increases the probability of being elected. If the observed signals are identical (with probability $\pi>\frac{1}{2}$ ),$x_{2}=x_{g g}^{*}$ is voters' preferred platform and party 1 is never elected under the deviation. Hence, the probability of being elected could be at most $1-\pi<1 / 2$. The only potentially profitable deviation must therefore induce better expected policies, which is only possible under conflicting signals (as the policy is already optimal for identical signals). Such a deviation is profitable under the assumed beliefs, if there exists an $\alpha>0$ satisfying

$$
\pi u\left(\beta_{g g}, x_{g g}^{*}\right)+(1-\pi)\left[u(1 / 2, D / 2-\alpha)+f_{1}\right]=\pi u\left(\beta_{g g}, x_{g g}^{*}\right)+(1-\pi) u\left(1 / 2, x_{g g}^{*}\right)+f_{1} / 2 .
$$

However, if the deviation is profitable for $x_{1} \in(D / 2-\alpha, D / 2)$, it is also profitable for $x_{1} \in(D / 2, D / 2+\alpha)$ under the assumed beliefs as policies equidistant from $D / 2$ are equally good when $\mu=1 / 2$. This implies that any policy in this interval would also be a profitable deviation after observing $s_{1}=b$ under some beliefs. As, by (ii) we know that it is possible to construct out-of-equilibrium beliefs satisfying the intuitive criterion such that the deviation is not profitable, the equilibrium always exists.

Proof of Proposition 3. In equilibrium, both parties are elected with equal probability and the implemented policy is $D / 2$. We study deviations by party 1 . First, note that it is easy to construct out-of-equilibrium beliefs satisfying the intuitive criterion if a deviation to some $x_{1} \neq D / 2$ is profitable for some beliefs after observing $s_{1}=b$ and $s_{1}=g$. Indeed, if voters ignore the signal received by party $1, \hat{s}_{1}=n$, the party is never elected, and such beliefs satisfy the intuitive criterion.

Hence, for a deviation to $x_{1}^{\prime} \in\left[0, \frac{D}{2}\right)$ to be profitable after observing $s_{1}=g$, it must be that (i) the deviation is profitable after observing $s_{1}=g$ for voters beliefs $\hat{s}_{1}\left(x_{1}^{\prime}\right)=g$, (ii) $x_{1}^{\prime}$ is never a profitable deviation after observing $s_{1}=b$. We want to identify a value of $f_{1}=f_{g}^{p}$ such that for all $f_{1}>f_{g}^{p}$ there is no deviation satisfying (i) and (ii).

(i) We identify $\tilde{x}_{g}$ such that there is a profitable deviation to $x_{1}^{\prime} \in\left(\tilde{x}_{g}, D / 2\right)$ but no profitable deviation to $x_{1}^{\prime}<\tilde{x}_{g}$ after observing $s_{1}=g$. For a deviation to be profitable for party 1 under some beliefs, $x_{1}^{\prime}$ must be in the range of values of $x$ strictly preferred by voters to $D / 2$ if $\hat{s}_{1}\left(x_{1}^{\prime}\right)=g$, so that their beliefs that the state of the world is $\mathrm{G}$ are $\mu\left(x_{1}, D / 2\right)=\beta(g, n)=p$. The minimum value of $x$ satisfying this condition is defined 
by:

$$
u(p, D / 2)=u(p, x)
$$

$x=\frac{D}{2}(3-4 p)$. As we assume the policy space is comprised between 0 and 1 , we find $\tilde{x}_{g}=\max \left\{\frac{D}{2}(3-4 p), 0\right\}$, so that $\tilde{x}_{g}=0$ for all $p>3 / 4$. If the deviation is preferred by voters, it is also preferred by party 1 as it gets elected with probability $\sigma=1$ and implements a better policy.

(ii) For party 1 to benefit from a deviation to $x_{1}^{\prime} \in\left(\tilde{x}_{g}, D / 2\right)$ after observing $s_{1}=b$, it must be that $\hat{s}_{1}\left(x_{1}^{\prime}\right)=g$. Else, the party is never elected. The worst policy outcome in this range after observing $s_{1}=b$ is $\tilde{x}_{g}$. Hence, if a deviation to $\tilde{x}_{g}$ is profitable, all deviations to $x_{1}^{\prime} \in\left(\tilde{x}_{g}, D / 2\right)$ are profitable.

A deviation to $\tilde{x}_{g}$ is profitable under some beliefs after observing $s_{1}=b$ whenever

$$
f_{1}+u\left(1-p, \tilde{x}_{g}\right)>\frac{f_{1}}{2}+u(1-p, D / 2)
$$

which yields

$$
f_{g}^{p}= \begin{cases}2 D^{2}(2 p-1)^{2} & \text { if } p<3 / 4 \\ \frac{D^{2}}{4}(4 p-1) & \text { if } p \geq 3 / 4 .\end{cases}
$$

Hence, for all values of $f_{1}>f_{g}^{p}$, any deviation that is profitable after observing $s_{1}=g$ is also profitable after observing $s_{1}=b$, so that it is possible to construct out-ofequilibrium beliefs satisfying the intuitive criterion such that the deviation is not profitable.

We can similarly identify a maximum value of $x$ such that voters are indifferent between policy $\tilde{x}_{b}$ and policy $D / 2$ if they believe party 1 observed $s_{1}=b, \tilde{x}_{b}=\min \left\{\frac{D}{2}(4 p-\right.$ $1), 1\}$. It is possible to show that a deviation to $\tilde{x}_{b}$ after observing $s_{1}=b$ is profitable if $f_{1}<f_{b}^{p}$,

$$
f_{b}^{p}= \begin{cases}2 D^{2}(2 p-1)^{2} & \text { if } p<\frac{2+D}{4 D} \\ \frac{(2-D)(2+(4 p-3) D)}{4} & \text { if } p \geq \frac{2+D}{4 D} .\end{cases}
$$

We define $f^{p}=\min \left\{f_{g}^{p}, f_{b}^{p}\right\}$. From the above we have proven that, if for both parties $f_{i}>f^{p}$, it is possible to specify out-of-equilibrium beliefs satisfying the intuitive criterion such there is no profitable deviation from the pandering equilibrium. All deviations that are profitable under some beliefs after observing $s_{1}=g$ (resp. $b$ ) are also profitable under some beliefs if $s_{1}=b$ (resp. $g$ ).

\section{References}

Ambrus, A., Baranovskyi, V. and Kolb, A. (2017) A delegation-based theory of expertise, Working paper 
Ansolabehere, S. and Konisky, D.M. (2014) Cheap and clean: how Americans think about energy in the age of global warming. Mit Press.

Arzheimer, K. (2009) Contextual factors and the extreme right vote in Western Europe, 1980-2002. American Journal of Political Science, 53(2), 259-275.

Bagwell, K., and Ramey, G. (1991) Oligopoly limit pricing. The RAND Journal of Economics, 155-172.

Banks, J. S., and Sobel, J. (1987) Equilibrium selection in signaling games. Econometrica, 55(3), 647-661.

Barnosky, A.D., Hadly, E.A., Bascompte, J., Berlow, E.L., Brown, J.H., Fortelius, M., Getz, W. M., Harte, J., Hastings, A., Marquet, P.A. and others (2012) Approaching a State Shift in Earths Biosphere, Nature, 486, 7401, 52-58.

Bernhardt, D., Duggan, J. and Squintani, F. (2009) The case for responsible parties, American Political Science Review, 103(4), 570-587.

Bosetti, V., Weber, E., Berger, L., Budescu, D. V., Liu, N., and Tavoni, M. (2017) COP21 climate negotiators responses to climate model forecasts, Nature Climate Change, 7(3), 185.

Callander, M. (2008) Political Motivations, The Review of Economic Studies, 75, 671-697.

Calvert, R. (1985) Robustness of the multidimensional voting model: candidate motivations, uncertainty, and convergence, American Journal of Political Science, 29(1), 9-95.

Cho, I-K., and Kreps, D. (1987) Signaling Games and Stable Equilibria, Quarterly Journal of Economics, 102, 179-221.

Cook, J., Oreskes, N., Doran, P.T., Anderegg, W.R., Verheggen, B., Maibach, E.W., Carlton, J.S., Lewandowsky, S., Skuce, A.G., Green, S.A. and Nuccitelli, D. (2016) Consensus on consensus: a synthesis of consensus estimates on human-caused global warming, Environmental Research Letters, 11(4), pp.1-7.

Crawford, V., and J. (1982) Strategic information transmission, Econometrica, 50(6), 
1431-1451.

Crawford, V. P., Gneezy, U., and Rottenstreich, Y. (2008) The power of focal points is limited: Even minute payoff asymmetry may yield large coordination failures, American Economic Review, 98(4), 1443-58.

Cukierman, A., and Tommasi M. (1998) When does it take a Nixon to go to China?, American Economic Review, 88(1), 180-197.

Feddersen, T. and Pesendorfer, W. (1997) Voting behavior and information aggregation in elections with private information, Econometrica, 65, 1029-1058.

Felgenhauer, M. (2012) Revealing information in electoral competition, Public Choice, $153,55-68$.

Gratton, G. (2014) Pandering and Electoral Competition, Games and Economic Behavior, 84, 163-179.

Grossman, S. J., and M. Perry (1986) Perfect Sequential Equilibrium, Journal of Economic Theory, 39, 97119.

Guber, D. L. (2013) A Cooling Climate for Change? Party Polarization and the Politics of Global Warming. American Behavioral Scientist, 57(1), 93-115.

Harsanyi, J. C., and Selten, R. (1988). A general theory of equilibrium selection in games, MIT Press Books.

Heidhues, P. and Lagerlöf, J. (2003) Hiding information in electoral competition, Games and Economic Behavior, 42, 48-74.

Hornsey, M. J., Harris, E. A., Bain, P. G., \& Fielding, K. S. (2016) Meta-analyses of the determinants and outcomes of belief in climate change. Nature Climate Change.

Hummel, P. (2010) Flip-flopping from primaries to general elections. Journal of Public Economics, 94(11-12), 1020-1027.

Hummel, H. (2007) A survey of involvement of 15 European States in the Iraq war 2003. Dusseldorf: Research Project on Parliamentary Control of Security Policy. 
Joskow, P.L., Schmalensee, R. \& Bailey, E.M. (1998) The market for sulfur dioxide emissions. American Economic Review, 669-685.

Kartik, N., Squintani, F. and Tinn, K. (2015) Information revelation and pandering in elections, mimeo.

Leslier, J.-F. and Van der Straten, K. (2004) Electoral competition under imperfect information, Economic Theory, 24, 419-446.

Loertscher, S. (2012) Location Choice and Information Transmission, mimeo. University of Melbourne.

Lupia, A. (2013) Communicating science in politicized environments, Proceedings of the National Academy of Sciences, 110(Supplement 3), 14048-14054.

Martinelli, C. (2001) Elections with privately informed parties and voters, Public Choice, $108,147-167$.

Pulzer, P. (2003) The devil they know: The German federal election of 2002, West European Politics, 26(2), pp.153-164.

Schultz, C. (1996) Polarization and inefficient policies, The Review of Economic Studies, 63, 331-343.

Schmidt, D., Shupp, R., Walker, J. M., and Ostrom, E. (2003) Playing safe in coordination games: the roles of risk dominance, payoff dominance, and history of play, Games and Economic Behavior, 42(2), 281-299.

Strömberg, D. (2004) Mass media competition, political competition, and public policy. The Review of Economic Studies, 71, 265-284.

Tol, R. S. (2011) Regulating knowledge monopolies: the case of the IPCC, Climatic Change, 108(4), 827-839.

Wittman, D. (1983) Candidate motivation: A synthesis of alternative theories, American Political Science Review, 77(1), 142-157. 